\title{
Viral and Cellular Proteins Involved in Coronavirus Replication
}

\author{
S. T. Shi • M. M. C. Lai $(\bowtie)$ \\ Department of Molecular Microbiology and Immunology, \\ University of Southern California, Keck School of Medicine, 2011 Zonal Avenue, \\ Los Angeles, CA 90033, USA \\ michlai@hsc.usc.edu
}

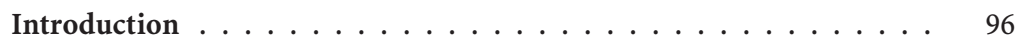

2 Viral Proteins in Coronavirus Replication . . . . . . . . . . . . . . 99

2.1 The Polymerase Gene Products . . . . . . . . . . . . . . . . . . . . 100

2.1.1 RNA-Dependent RNA Polymerase . . . . . . . . . . . . . . . . . . . . . 102

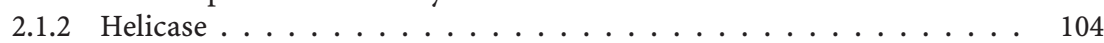

2.1 .3 Proteases . . . . . . . . . . . . . . . . . . . 105

2.1.4 Other Polymerase Gene Proteins . . . . . . . . . . . . . . . . . . . . 107

2.2 The N Protein . . . . . . . . . . . . . . . . . . . . . 108

3 Cellular Proteins in Coronavirus Replication . . . . . . . . . . . . . 109

$3.1 \quad$ HNRNP A $1 \ldots \ldots \ldots \ldots \ldots$

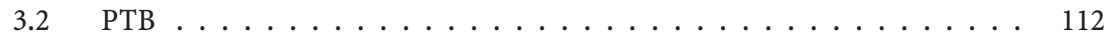

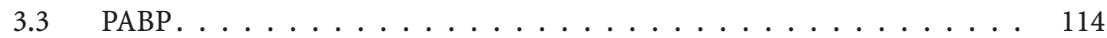

3.4 Mitochondrial Aconitase . . . . . . . . . . . . . . . . . . . . 115

3.5 Other Cellular Proteins. . . . . . . . . . . . . . . . . . . . . 116

3.6 Proposed Functions of Cellular Proteins . . . . . . . . . . . . . . . 117

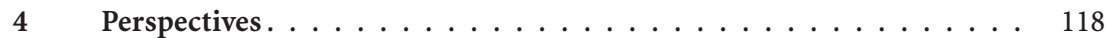

References. . . . . . . . . . . . . . . . . . . . . . . . . 119

Abstract As the largest RNA virus, coronavirus replication employs complex mechanisms and involves various viral and cellular proteins. The first open reading frame of the coronavirus genome encodes a large polyprotein, which is processed into a number of viral proteins required for viral replication directly or indirectly. These proteins include the RNA-dependent RNA polymerase (RdRp), RNA helicase, proteases, metal-binding proteins, and a number of other proteins of unknown function. Genetic studies suggest that most of these proteins are involved in viral RNA replication. In addition to viral proteins, several cellular proteins, such as heterogeneous nuclear ribonucleoprotein (hnRNP) A1, polypyrimidine-tract-binding (PTB) protein, poly(A)-binding protein (PABP), and mitochondrial aconitase (m-aconitase), have been identified to interact with the critical cis-acting elements of coronavirus replication. Like many other RNA viruses, coronavirus may subvert these cellu- 
lar proteins from cellular RNA processing or translation machineries to play a role in viral replication.

\section{1}

\section{Introduction}

Studies of diverse groups of positive-stranded RNA viruses reveal that they employ common strategies for replication, although the precise nature of these proteins varies for each virus (Pogue et al. 1994). In gener$\mathrm{al}$, the formation of viral translation and RNA replication complexes require multiple viral and cellular proteins. By analogy with the phage $\mathrm{Q} \beta$, which recruits four host (bacterial) proteins to be an integral part of the replicase complex together with the viral polymerase (Blumenthal and Carmichael 1979), it is likely that replication complexes of positivestranded RNA viruses consist of both virus- and host-encoded proteins. In addition, viral and cellular proteins interact with various cis-acting elements on viral RNAs and play essential roles in the regulation of viral replication. They may mediate the cross talk between the $5^{\prime}$ and $3^{\prime}$ ends of the viral RNA and bring other distant cis-acting elements close together to carry out complex processes, such as subgenomic RNA transcription, coupling between translation and RNA replication, and asymmetric production of excess genomic positive- over negative-strand RNAs. The switch between translation and replication in poliovirus has been shown to involve the cellular protein poly $(\mathrm{rC})$-binding protein (PCBP), which upregulates viral translation, and the viral protein $3 \mathrm{CD}$, which represses viral translation and promotes negative-strand synthesis (Gamarnik and Andino 1998). Identification of the roles of viral and cellular proteins should provide valuable insights into the mechanisms of viral replication.

The replication of the genome is considered as the most fundamental aspect of the biology of positive-stranded RNA viruses. Like all other positive-stranded RNA viruses, coronavirus replicates its genome through the synthesis of a complementary negative-strand RNA using the genomic RNA as a template. The negative-strand RNA, in turn, serves as the template for synthesizing more progeny positive-strand RNAs. Analysis of the structure of mouse hepatitis virus (MHV) defective-interfering (DI) RNAs indicates that approximately 470 nucleotides (nt) at the $5^{\prime}$ terminus, $436 \mathrm{nt}$ at the $3^{\prime}$ terminus, and about 135 internal nt are required for coronavirus DI RNA replication and suggests that these sequences contain signals necessary for viral RNA replication 
(Kim et al. 1993; Kim and Makino 1995b; Lin and Lai 1993; Lin et al. 1996). Both of the $5^{\prime}$ and $3^{\prime}$ ends of the genome are necessary for positive-strand synthesis (Kim et al. 1993; Lin and Lai 1993), whereas the cis-acting signals for the synthesis of negative-strand RNA exist within the last $55 \mathrm{nt}$ and the poly(A) tail at the $3^{\prime}$ end of the MHV genome (Lin et al. 1994). One unique feature of coronaviruses is the expression of their genetic information by transcription of a $3^{\prime}$ coterminal nested set of subgenomic mRNAs that contain a common $5^{\prime}$ leader sequence derived from the $5^{\prime}$ end of the RNA genome. The interaction between the leader sequence and an intergenic (IG) sequence upstream of each open reading frame $(\mathrm{ORF})$, also named transcription-regulating sequence (TRS), is required for the transcription of subgenomic mRNAs (Chang et al. 1994; Liao and Lai 1994; Zhang and Lai 1995b). Logically, these cisacting sequences for viral genomic RNA replication and subgenomic RNA transcription serve as ideal signals to recruit viral factors and possibly cellular proteins for the formation of the RNA replication and transcription complex.

Apart from the findings that continuous synthesis of viral proteins is a prerequisite for the synthesis of both positive- and negative-strand RNA and subgenomic mRNAs (Perlman et al. 1986; Sawicki and Sawicki 1986), little information is currently available concerning the identities and functions of the viral proteins that participate in coronavirus replication. Because of the unparalleled size of the coronavirus RNA genome, genetic approaches to the analysis of replicase gene function have been limited to date. Nevertheless, studies of the temperature-sensitive mutants of coronavirus demonstrate the importance of ORF 1 polyprotein (also known as the polymerase or replicase protein) in coronavirus RNA synthesis and suggest that different domains of this polyprotein are involved in different steps of viral RNA synthesis (Baric et al. 1990a; Fu and Baric 1994; Leibowitz et al. 1982; Schaad et al. 1990). Evolutionarily, the virus genome is composed of relatively constant replicative genes that are indispensable for viral replication and more flexible genes coding for virion structural proteins and various accessory proteins (Koonin and Dolja 1993). Despite the high mutation frequency that is typical of RNA viruses, viral proteins mediating the replication and expression of virus genomes contain arrays of conserved sequence motifs. Proteins with such motifs include RdRp, putative RNA helicase, chymotrypsin-like and papain-like proteases, and metal-binding proteins, all of which are present in the coronavirus ORF 1 polyprotein as shown by sequence comparisons (Bonilla et al. 1994; Bredenbeek et al. 1990; Gorbalenya et al. 1989b; Lee et al. 1991). Strategically located as the 
$5^{\prime}$-most gene in the viral genome, the coronavirus ORF 1 is translated into a large polyprotein immediately upon virus entry and processed by viral proteases into functional proteins, which are responsible for RNA replication and transcription. The processing scheme of the coronavirus ORF 1 polyprotein has been largely delineated by a number of recent studies. As a result, the functions of the domains that have not been identified before are beginning to emerge. In addition to the proteins with apparent enzymatic activities required for viral RNA synthesis, a number of other coronavirus proteins have also been implicated in viral replication.

Many studies have shown that viruses use cellular proteins for multiple purposes in their replication cycles, including the attachment and entry into the cells, the initiation and regulation of RNA replication/ transcription, the translation of their mRNAs, and the assembly of progeny virions. Because many aspects of the replication cycles of different types of viruses are unique, the cellular proteins used by different types of viruses also differ. Nevertheless, viruses typically subvert the normal components of cellular RNA processing or translation machineries to play an integral or regulatory role in the replication/transcription and translation of viral RNA (Lai 1998). These cellular proteins include, but are not limited to:

1. Heterogeneous nuclear ribonucleoproteins and other RNA processing factors: hnRNP A1 (Black et al. 1995, 1996; Li et al. 1997; Shi et al. 2000; Wang et al. 1997) and other hnRNP type A/B proteins (Bilodeau et al. 2001; Caputi et al. 1999; Shi et al. 2003), hnRNP C (Gontarek et al. 1999; Sokolowski and Schwartz 2001; Spangberg et al. 2000), hnRNP E (PCBP) (Gamarnik and Andino 1997; Parsley et al. 1997), hnRNP H (Caputi and Zahler 2002), hnRNP I (PTB) (Black et al. 1995, 1996; Chung and Kaplan 1999; Gontarek et al. 1999; Hellen et al. 1994; Ito and Lai 1997; Li et al. 1999; Wu-Baer et al. 1996), hnRNP L (Gutierrez-Escolano et al. 2000; Hahm et al. 1998), HuR (Spangberg et al. 2000), and Lsm1p-related protein (Diez et al. 2000).

2. Translation factors: elongation factors EF- $1 \alpha$ (Blackwell and Brinton 1997; Harris et al. 1994; Joshi et al. 1986), $-\beta$ and $-\gamma$ (Das et al. 1998), EF-Tu (Blumenthal and Carmichael 1979), and eukaryotic initiation factor eIF-3 (Osman and Buck 1997; Quadt et al. 1993).

3. Noncanonical translation factors: hnRNP Al, PTB, and La antigen (Meerovitch et al. 1993; Pardigon and Strauss 1996; Svitkin et al. 1996).

4. Cytoskeletal or chaperone proteins: tubulin (Huang et al. 1993; Moyer et al. 1990; Moyer et al. 1986), actin (De et al. 1991), and heat shock protein (Oglesbee et al. 1996). 
These cellular proteins typically bind to viral RNAs or polymerase to form replication or translation complexes (Lai 1998). Remarkably, most of them can interact with RNAs of several different viruses or bind to viral RNA in one virus but associate with viral polymerase in another.

Coronavirus RNA synthesis, including replication of viral genome and transcription of subgenomic mRNAs, has been shown to be regulated by several viral RNA elements, including $5^{\prime}$-untranslated region (UTR), cis- and trans-acting leader RNAs (Liao and Lai 1994; Zhang et al. 1994; Zhang and Lai 1995b), IG sequence (Makino et al. 1991), and $3^{\prime}$-UTR (Lin et al. 1996). Biochemical evidence suggests that these regulatory sequences likely interact with each other either directly or indirectly, probably through protein-RNA and protein-protein interactions involving both viral and cellular proteins (Zhang and Lai 1995b). Indeed, hnRNP A1 (Huang and Lai 2001; Li et al. 1997; Shi et al. 2000), PTB (Huang and Lai 1999; Li et al. 1999), PABP (Spagnolo and Hogue 2000), and mitochondrial aconitase (Nanda and Leibowitz 2001), have been identified as binding specifically to the known cis-acting regulatory sequences. The functional importance of hnRNP A1 (Shi et al. 2000) and PTB (Huang and Lai 1999) in viral RNA synthesis has also been established, further supporting the notion that cellular proteins play an integral or regulatory role in viral replication.

Viruses invariably rely on cellular architecture as an important structural element of their replication machineries. The replication complexes of numerous positive-stranded RNA viruses have been found to be membrane associated (Bienz et al. 1994; Chambers et al. 1990; Froshauer et al. 1988; Miller et al. 2001; Schwartz et al. 2002; van Dinten et al. 1996). Thus, many cellular membrane proteins are expected to serve as scaffolds to provide support for the formation of viral replication complexes, for localized protein translation, and for viral assembly. Very little is currently known about these cellular factors. In this chapter, we focus on the proteins that are the integral parts of the replication complexes. Left out are the cellular factors involved in other aspects of viral replication, such as virus entry and virus assembly.

\section{2}

\section{Viral Proteins in Coronavirus Replication}

Although the mechanism of coronavirus RNA replication is still controversial, the consensus is that coronavirus RNA replication is directed by cis-acting sequences present on the viral RNAs with the help of trans- 
acting factors encoded by the virus. Indeed, continuous protein synthesis is required for RNA synthesis, due to the fact that the application of inhibitors of protein synthesis at any time during the viral life cycle inhibits viral RNA synthesis (Perlman et al. 1986; Sawicki and Sawicki 1986). A similar observation has been made with an inhibitor of cysteine protease, which inhibits the processing of the MHV ORF 1 (termed the polymerase or the replicase gene) polyprotein (Kim et al. 1995), suggesting that continuous production of the polymerase gene products is required for viral RNA synthesis. The precise nature of many of these products, however, is largely unknown.

\section{1}

\section{The Polymerase Gene Products}

The coronavirus polymerase gene accounts for approximately two-thirds of the genome. It contains two overlapping ORFs, ORF 1a and ORF $1 \mathrm{~b}$, which overlap by $76 \mathrm{nt}$ (Fig. 1). The expression of the downstream
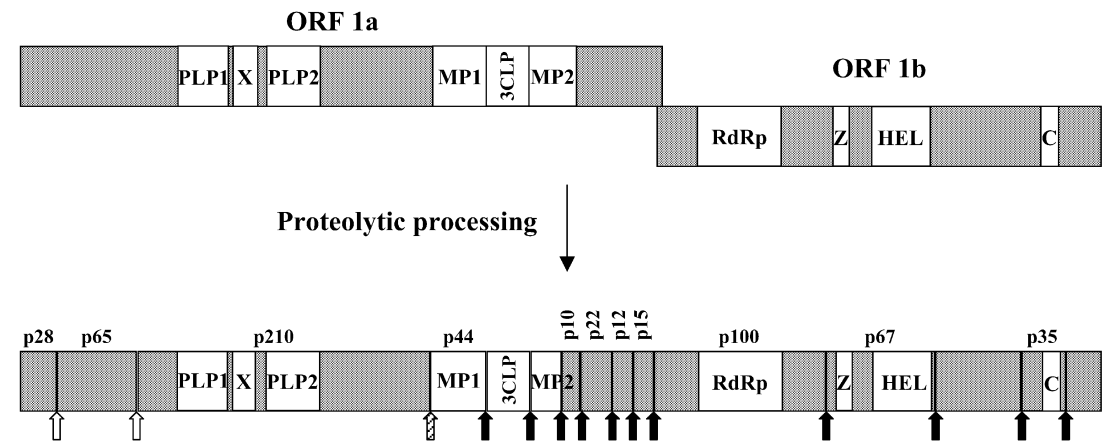

Genetic complementation groups

A

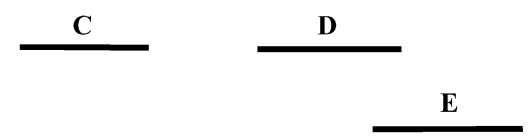

B

Fig. 1. The domain structure and processing scheme of the MHV polymerase gene products and the approximate location of genetic complementation groups (Baric et al. 1990a). $P L P$, papain-like protease; 3CLP, 3C-like protease; $M P$, membrane protein; $R d R p$, RNA-dependent RNA polymerase; $Z$, zinc-binding domain; HEL, helicase; $C$, conserved domain. The open, hatched, and closed arrows indicate the PLP1, PLP2, and 3CLP cleavage sites, respectively 
ORF $1 \mathrm{~b}$ is mediated by a ribosomal frameshift event that is aided by the formation of a pseudoknot structure within the overlapping region (Bredenbeek et al. 1990; Brierley et al. 1987; Herold and Siddell 1993). To date, the full-length product of ORF 1 has not been detected in coronavirus-infected cells, most probably because it is cotranslationally and auto-proteolytically processed into numerous intermediates and mature nonstructural proteins. Based on the primary sequences of several different coronaviruses, the degree of amino acid identity for this gene product is greater than that is observed for any other coronavirus gene products. A combination of computer-based motif prediction and experimental analysis has identified a number of functional domains in the ORF 1 polyprotein (Fig. 1) (Gorbalenya et al. 1991; Lee et al. 1991). ORF 1a contains the papain-like cysteine proteases (PLPs), a chymotrypsin/ picornaviral 3C-like protease (3CLP), and membrane-associated proteins (MP). The more conserved ORF $1 \mathrm{~b}$ includes domains for an RdRp, a zinc-finger nucleic acid-binding domain (metal-binding domain), and a nucleoside triphosphate (NTP)-binding/helicase domain. Both the synthesis and the processing of the ORF 1 polyprotein have been shown to be essential throughout infection to sustain RNA synthesis and virus replication (Denison et al. 1995b; Kim et al. 1995; Shi et al. 1999).

The importance of the polymerase gene products in viral replication has been established by the study of temperature-sensitive (ts) mutants, which are a practical tool for investigating the roles of viral proteins in replication. The ts mutants are grouped into two categories, $\mathrm{RNA}^{-}$and $\mathrm{RNA}^{+}$, based on the ability of these mutants to support viral RNA synthesis at the restrictive temperature (Leibowitz et al. 1982; Robb and Bond 1979). Complementation analysis of ts mutants suggests that at least five $\mathrm{RNA}^{-}$complementation groups are encoded in the MHV genome (Baric et al. 1990a; Koolen et al. 1983; Leibowitz et al. 1982; Martin et al. 1988; Schaad et al. 1990). All of the $\mathrm{RNA}^{-}$complementation groups are mapped within the ORF 1 region, suggesting that the coronavirus ORF 1 encodes all of the proteins required for viral RNA replication. Different complementation groups within MHV ORF 1 have been demonstrated to affect distinct steps of RNA synthesis, including the synthesis of leader RNA, negative-strand RNA, and positive-strand RNA, suggesting that different steps of RNA synthesis require different viral proteins (Baric et al. 1990b). Among the five $\mathrm{RNA}^{-}$complementation groups, A, B, C, D, and E, identified by Baric et al. (Fig. 1) (Baric et al. 1990a), groups A and B are defective in the synthesis of all viral RNAs, whereas the rest of the groups are only defective in certain steps of viral RNA synthesis. The group C mutants encode a function required early 
in viral transcription to synthesize negative-strand RNA, whereas the group E mutants are blocked at a later stage in the virus growth cycle. The group D mutants are incapable of subgenomic mRNA transcription. Taken together, at least four cistrons are required for positive-strand RNA synthesis whereas the group $C$ cistron functions during negativestrand RNA synthesis. A comparison of three disparate panels of MHV ORF 1 mutants, one for JHM (Robb and Bond 1979) and two for A59 (Koolen et al. 1983; Schaad et al. 1990), concluded that there are at least eight genetically complementable, trans-acting functions encoded by ORF 1 (Stalcup et al. 1998).

Genetic recombination analysis revealed that the five $\mathrm{RNA}^{-}$complementation groups of $\mathrm{MHV}$ are arranged in alphabetical order in the $5^{\prime}$ to $3^{\prime}$ direction, with some overlaps between the group A/B and D/E mutants (Fig. 1) (Baric et al. 1990a, b). Group A most likely includes the PLP1 and PLP2 domains, whereas group B encompasses the 3CLP domain. Group C spans the ORF 1a/ORF 1b junction, including the site of ribosomal frameshifting and the N-terminal part of the putative RdRp. Group D is mapped approximately in the middle part of the ORF $1 \mathrm{~b}$, possibly encoding the C-terminal part of the putative RdRp and the helicase domain. Group $\mathrm{E}$ is located at the $\mathrm{C}$ terminus of ORF $1 \mathrm{~b}$, about 20-22 kb from the $5^{\prime}$ end of the genome ( $\mathrm{Fu}$ and Baric 1994). Further characterization of the ts mutants showed that one group $\mathrm{C}$ mutant carries a mutation in the $5^{\prime}$ end of ORF $1 \mathrm{~b}$ encoding the putative RdRp, which is the only mutation found in a domain with an assigned function. Because most of the mutations in other ts mutants have not been identified, it is still not possible to correlate all the genetic defects with the processed products of the ORF 1 polyprotein.

Studies of the localization and interactions of MHV replicase proteins in infected cells have also provided critical insights into the possible roles of these proteins during viral replication. The localization of polymerase gene products, including PLP1 and PLP2, 3CLP, RdRp, and helicase, to cytoplasmic foci active in viral RNA synthesis has been well documented, suggesting that they may participate in the formation and function of the viral replication complexes (Denison et al. 1999; Shi et al. 1999; van der Meer et al. 1999).

\subsection{1}

\section{RNA-Dependent RNA Polymerase}

The RdRp is the most conserved domain of all RNA viruses and is certainly the most fundamental component of the viral replication machin- 
ery. It functions as the catalytic subunit of the viral replicase required for the replication of all positive-stranded RNA viruses (Buck 1996). The vast majority of RdRps, including the coronavirus RdRp, have been identified solely on the basis of sequence similarity. Most viral RNA polymerases contain a signature GDD motif, which is considered to be the most characteristic sequence of the RdRps of positive-stranded RNA viruses. In coronavirus, an SDD motif is detected instead of GDD; the effect of this substitution on the activity of coronavirus RdRp is not clear (Gorbalenya et al. 1989b). Based on sequence analysis, the coronavirus $R d R p$ is encoded by the $5^{\prime}$ end of the ORF 1 b gene, synthesized as part of the gene 1 polyprotein, and processed by cysteine proteases into an approximately 100-kDa protein (Fig. 1) (Gorbalenya et al. 1989b; Lee et al. 1991). The viral proteins that contain the putative RNA polymerase domain have been detected by immunofluorescence or immunoprecipitation in cells infected with MHV (Shi et al. 1999; van der Meer et al. 1999), IBV (Liu et al. 1994), and HCoV-229E(Grotzinger et al. 1996) but it is not known whether they represent the functional RdRp.

Earlier studies on transmissible gastroenteritis virus (TGEV), bovine coronavirus (BCV), and MHV demonstrated viral polymerase activities in membrane fractions of virus-infected cells (Brayton et al. 1982, 1984; Dennis and Brian 1982; Mahy et al. 1983). Two temporally and enzymatically distinct RdRp activities have been detected in MHV-infected cells (Brayton et al. 1982), suggesting that the enzyme represents two different species of RNA polymerase that perform different roles in virus-specific RNA synthesis. The early polymerase is most likely responsible for negative-strand RNA synthesis, whereas the late polymerase is responsible for the positive-stranded RNA synthesis (Brayton et al. 1984). It is unknown whether the protein components of these two complexes are different or whether the same polymerase is modified by other viral or cellular proteins to perform distinct functions. Because coronaviruses are known to have a unique mechanism of subgenomic RNA synthesis quite distinct from that of genome replication, it is possible that the viruses could have more than one RNA polymerase. After the initial detection of polymerase activities in the fractions of coronavirus-infected cells, several in vitro RNA synthesis systems were also reported (Baker and Lai 1990; Compton et al. 1987; Leibowitz and DeVries 1988). The nature of the polymerases in these systems, however, has not been characterized.

The catalytic activity of the coronavirus $\mathrm{RdRp}$ has so far not been demonstrated biochemically. In fact, only a handful of viral RdRps, such as $\mathrm{Q} \beta$ replicase subunit II (Landers et al. 1974), poliovirus 3D pol pro- 
tein (Neufeld et al. 1991; Rothstein et al. 1988; Van Dyke and Flanegan 1980), hepatitis C virus NS5B protein (Behrens et al. 1996; Lohmann et al. 1997; Yuan et al. 1997), dengue virus NS5 protein (Tan et al. 1996), and tobacco vein mottling virus (TVMV) nuclear inclusion protein NIb (Hong and Hunt 1996), have been shown to possess RNA replicating activities in vitro. It is likely that the extremely hydrophobic nature of the coronavirus RdRps prevents the purification and biochemical characterization of this protein. Thus, the precise role of coronavirus RdRps in viral RNA synthesis has not been established.

\subsection{2}

\section{Helicase}

The RNA helicase is the second most conserved component of the RNA virus replication machinery (Gorbalenya et al. 1988, 1989a; Gorbalenya and Koonin 1989; Koonin and Dolja 1993). Nearly all double-stranded and positive-stranded RNA viruses are predicted to encode putative helicases (Gorbalenya and Koonin 1989). RNA helicases are a diverse class of enzymes that use the energy of NTP hydrolysis to unwind duplex RNA. There is extensive genetic evidence suggesting a key function for helicases in the life cycle of positive-stranded RNA viruses (Buck 1996; Kadare and Haenni 1997). They are involved in virtually every aspect of RNA metabolism, including transcription, splicing, translation, export, ribosome biogenesis, mitochondrial gene expression, and the regulation of mRNA stability (de la Cruz et al. 1999; Linder and Daugeron 2000; Lohman and Bjornson 1996; Schmid and Linder 1992). The idea of involvement of RNA helicase in RNA replication came from the observation that helicase mutants of BMV are defective in template recruitment for RNA replication and the synthesis of negative-strand or subgenomic RNA (Ahola et al. 2000).

The RNA helicase domains of coronaviruses are encoded by ORF $1 \mathrm{~b}$ and processed by 3CLP (Denison et al. 1999). They have been proposed to represent a separate phylogenetic lineage of the RNA virus superfamily 1 (SF1) helicases, which include the majority of putative RNA virus helicases (Gorbalenya and Koonin 1989; Kadare and Haenni 1997; Koonin and Dolja 1993). The putative MHV RNA helicase, which is processed from the ORF $1 \mathrm{~b}$ polyprotein by $3 \mathrm{CLP}$, has been detected in MHV-infected cells throughout the viral life cycle (Denison et al. 1999). Numerous attempts to detect the predicted RNA duplex-unwinding activity of these proteins have failed until recently when duplex-unwinding activity was observed for the human coronavirus (HCoV) helicase, pro- 
viding valuable insights into the functions of this protein in viral replication (Seybert et al. 2000). Biochemical characterization revealed that this helicase has both RNA and DNA duplex-unwinding activities with a $5^{\prime}$ to $3^{\prime}$ polarity, in contrast to the previously characterized RNA virus SF2 helicases. A zinc finger/nucleic acid-binding domain, which has been found in numerous cellular helicases (Fig. 1) (Gorbalenya and Koonin 1993), is also present in the coronavirus ORF 1b, upstream of the helicase domain, but it is not known whether it contributes to the activity of the coronavirus helicase.

Although there is no direct evidence indicating the involvement of the helicase in coronavirus RNA replication and transcription, the helicase was localized to the perinuclear sites where active viral RNA synthesis was observed (Denison et al. 1999). It was further detected by biochemical analysis in membrane fractions that contain viral RNAs, suggesting that helicase is a component of the viral replication complex (Bost et al. 2000, 2001; Denison et al. 1999; Sims et al. 2000). Furthermore, because double-stranded replicative intermediates are believed to be the predominant RNA structures in coronavirus RNA synthesis, it is tempting to speculate that, in analogy to models described for the DNA replisome (Baker and Bell 1998), the coronavirus helicase cooperates with the RdRp by providing the single-stranded RNA template for processive RNA synthesis. It is noteworthy that the vaccinia virus NPH-II RNA helicase was recently shown to be a highly processive enzyme that unwinds long duplex RNA structures, supporting the hypothesis that at least some viral RNA helicases might be directly involved in RNA replication (Jankowsky et al. 2000).

\subsection{3}

\section{Proteases}

The coronavirus replicase is translated from the genomic RNA as a large precursor polyprotein, which is then processed by viral proteases to generate functional replicase proteins. Whereas the RdRp and RNA helicase play direct roles in viral RNA synthesis, the proteases are involved in viral replication through the processing of viral polyproteins into mature products critical for the appropriate localization, assembly, and function of the replicase complex. They also play an important regulatory role in the generation of specific protein functions at certain stages of the viral life cycle. This controlled proteolysis is thought to be determined mainly by the substrate specificity of the proteases and the accessibility of cleavage sites in the context of specific intermediate products 
(van Dinten et al. 1997, 1999; Ziebuhr and Siddell 1999). Sequence analysis of coronavirus genomic RNA led to the prediction of two or three protease domains in ORF 1a: one or two PLPs and a 3CLP (Gorbalenya et al. 1991; Lee et al. 1991). All of these proteases have been shown to function during viral replication and drive the processing of the MHV ORF 1 replicase polyprotein into at least 15 products (Fig. 1) (Baker et al. 1989, 1993; Bonilla et al. 1994, 1995; Bost et al. 2000; Denison et al. 1992, 1995a, 1999; Gao et al. 1996; Lu et al. 1995, 1996, 1998; Lu and Denison 1997; Pinon et al. 1999; Schiller et al. 1998; Shi et al. 1999). Comparable, but distinct, proteolytic processing pathways have also been reported for some other coronaviruses, most notably IBV (Liu et al. 1994, 1998; Liu and Brown 1995) and HCoV-229E (Ziebuhr et al. 2000).

The coronavirus ORF 1 polyprotein can be divided into an N-terminal region that is processed by one or two PLPs and a C-terminal region that is processed by the 3CLP (Ziebuhr et al. 2000). The N-terminal region of the polyprotein spans from the initiator Met to the $\mathrm{N}$ terminus of the hydrophobic domain MP1 (Fig. 1). All coronaviruses, except IBV, encode two paralogous and sequentially positioned PLP1 and PLP2 that flank a conserved X domain from both sides (Fig. 1) (Gorbalenya et al. 1991; Lee et al. 1991). At least three proteins, p28, p65, and p210 (also known as $\mathrm{p} 240$ ), are produced from this region of the ORF 1a polyprotein in MHV (Denison and Perlman 1987; Denison et al. 1995a; Schiller et al. 1998). The MHV p210 protein is autocatalytically released through cleavages mediated by PLP1 at the N-terminal site (Bonilla et al. 1995, 1997) and PLP2 at the C-terminal site (Kanjanahaluethai and Baker 2000). PLP1 also cleaves the p28-p65 junction (Baker et al. 1989, 1993; Dong and Baker 1994; Hughes et al. 1995), which, except for IBV, is conserved in all coronaviruses (Herold et al. 1998). Accordingly, a PLP1-mediated cleavage at this site, resulting in the production of a small N-terminal protein (p9, p28 equivalent), was also detected in $\mathrm{HCoV}$-infected cells (Herold et al. 1998). The single IBV PLP corresponds to the PLP2 domain of other coronaviruses. It is part of a p195 protein, which is cleaved to produce an N-terminal product, p87 (Lim and Liu 1998; Lim et al. 2000).

Coronavirus PLPs contain a transcription factor-like zinc finger (Herold et al. 1999), suggesting that they might also be directly involved in coronavirus RNA synthesis. This hypothesis is strongly supported by a recent report showing the equine arteritis virus (EAV) nonstructural protein 1 , which is likely a distant homolog of the coronavirus PLPs, to 
be a transcriptional factor indispensable for subgenomic mRNA synthesis (Tijms et al. 2001).

The C-terminal part of the ORF 1 polyprotein encompasses all of the major conserved domains starting from the hydrophobic domain MP1 and extending to the $\mathrm{C}$ terminus of the replicase polyprotein. The 3CLP, flanked on either side by membrane-spanning regions MP1 and MP2 (Bonilla et al. 1994; Lee et al. 1991; Lu et al. 1995), is believed to be the principal viral protease responsible for the processing events leading to the formation of the viral replicase complex. At least 12 processing products, including the 3CLP itself, RdRp, and helicase, are generated by 3CLP-mediated cleavage (Fig. 1) (Gorbalenya et al. 1991; Lee et al. 1991). Treatment of infected cells with E64d, a known inhibitor of the 3CLP, results in the inhibition of viral RNA replication in these cells (Kim et al. 1995), demonstrating the importance of the action of the 3CLP in the events leading to viral replication. The importance of 3CLP cleavages was demonstrated with an infectious clone of the related arterivirus EAV (van Dinten et al. 1999). Introduction of mutations into the candidate ORF 1b 3CLP cleavage sites had drastic effects on RNA synthesis and virus replication. 3CLP has also been localized to the site of viral RNA synthesis by immunofluorescence staining and biochemical fractionation studies (Bost et al. 2000, 2001; Denison et al. 1999; Shi et al. 1999; Sims et al. 2000).

\subsection{4}

\section{Other Polymerase Gene Proteins}

Apart from the RdRp, helicase, and proteases, the identities of many of the ORF 1 products have not been established. Thus, their roles in viral replication remain unknown. By immunofluorescence staining and confocal microscopy, several studies have shown that a number of ORF 1a products, $\mathrm{p} 65, \mathrm{p} 10, \mathrm{p} 22, \mathrm{p} 12$, and $\mathrm{p} 15$, and an ORF $1 \mathrm{~b}$ product, $\mathrm{p} 35$, are associated with the site of viral RNA synthesis (Fig. 1) (Bost et al. 2000; Shi et al. 1999). However, biochemical studies revealed two distinct but tightly associated membrane populations, only one of which appears to be a site for viral RNA synthesis (Sims et al. 2000). p28, helicase, 3CLP, and nucleocapsid $(\mathrm{N})$ protein cosegregated with the viral RNA and, therefore, are likely to be the components of the viral replication complexes, whereas p65 and p22 are present in different membrane fractions and may serve roles during infection that are distinct from viral RNA transcription or replication (Sims et al. 2000). 
The hydrophobic domains, MP1 and MP2, within the ORF 1a polyprotein were postulated to mediate the association of the coronavirus replicase with cellular membrane structures. MP1 has indeed been detected in microsomal membranes (Pinon et al. 1997), but its role in membrane association and coronavirus replication is largely speculative. A recent study on the related arterivirus demonstrated that the EAV nonstructural proteins (nsp) 2 and 3, which contain one or two hydrophobic regions, induce the formation of double-membrane structures where EAV RNA synthesis takes place (Snijder et al. 2001). Similarly, the membrane proteins of coronavirus may serve to alter the cell architecture so that it is more favorable for viral replication.

\section{2}

\section{The N Protein}

The coronavirus $\mathrm{N}$ protein associates with the genomic RNA to form a helical nucleocapsid. In addition to its role as a major structural component of virions, $\mathrm{N}$ may also be involved in viral RNA replication and translation control. In an in vitro replication system for MHV, it was demonstrated that antibodies against the $\mathrm{N}$ protein could inhibit RNA synthesis (Compton et al. 1987). Optimal replication of the bovine coronavirus (BCV) DI RNA also requires the translation of most, if not all, of the $\mathrm{N}$ protein in cis (Chang and Brian 1996). Structural analysis of DI RNAs shows that the presence of gene 1 and $\mathrm{N}$ gene is sufficient for viral RNA replication (Kim and Makino 1995a). In addition, the MHV N protein was detected in membrane fractions containing viral RNA (Sims et al. 2000) and colocalized with putative replicase proteins in virusinfected cells, providing further support that $\mathrm{N}$ may be involved in RNA replication (Denison et al. 1999; van der Meer et al. 1999). However, a mutational study of an infectious cDNA clone of EAV, a close relative of coronavirus, reported that all structural proteins, including $\mathrm{N}$, are dispensable for genome replication and subgenomic mRNA transcription (Molenkamp et al. 2000). The coronavirus replicase gene products were also shown to be sufficient for discontinuous subgenomic mRNA transcription with a partial cDNA clone representing the $5^{\prime}$ and $3^{\prime}$ ends of the $\mathrm{HCoV}-229 \mathrm{E}$ genome, the $\mathrm{HCoV}-229 \mathrm{E}$ replicase gene, and a reporter gene located downstream of a regulatory element for coronavirus mRNA transcription (Thiel et al. 2001). The RNA replication levels observed in these systems are much lower than those containing the wild-type fulllength viral genome, indicating that factors other than the replicase polyprotein are required for efficient RNA replication. 
Because the $\mathrm{N}$ protein has the ability to interact with viral RNA, it most likely functions in viral RNA synthesis by binding to RNA and forming a ribonucleoprotein (RNP) complex. The $\mathrm{N}$ protein binds to the leader RNA sequences present at the $5^{\prime}$ end of genomic RNA and all six subgenomic mRNAs in MHV-infected cells (Baric et al. 1988; Nelson et al. 2000). Biochemical analysis measured a dissociation constant of $14 \mathrm{nM}$ for bacterially expressed MHV N-binding to the leader RNA (Nelson et al. 2000). The MHV negative-stranded RNA was also immunoprecipitated by the anti-N monoclonal antibody. These data indicate that the MHV N protein is associated with MHV-specific RNAs and RNA intermediates and may play an important functional role during MHV transcription and replication. Furthermore, the N-leader-RNA-containing RNP complexes were also immunoprecipitated from BCV-infected cells (Cologna et al. 2000). The interactions between the $\mathrm{N}$ protein and the RNA encompassing the N ORF may also contribute to the formation of the N-RNA complexes that are present in coronavirus-infected cells (Cologna et al. 2000).

The $\mathrm{N}$ protein of MHV is also involved in positive translational control (Tahara et al. 1993, 1998). It stimulated translation of a chimeric reporter mRNA containing an intact MHV $5^{\prime}$-untranslated region and the chloramphenicol acetyltransferase (CAT)-coding sequence. Preferential translation of viral mRNA in MHV-infected cells is stimulated in part by the interaction between the $\mathrm{N}$ protein and a 12-nt tract at the $3^{\prime}$ end of the leader.

Other coronavirus proteins, including structural protein hemagglutinin-esterase (HE) (Luytjes et al. 1988; Yokomori et al. 1991) and nonstructural proteins NS2 (Schwarz et al. 1990), NS4 and NS5 (Yokomori and Lai 1991), are not essential for coronavirus replication. However, it is not clear whether any of these proteins can modulate viral replication.

\section{3}

\section{Cellular Proteins in Coronavirus Replication}

Coronavirus replication involves not only the viral proteins, but also cellular proteins, which are subverted from the normal functions of the host to play roles in the viral replication cycle. No coronavirus proteins in the infected cell extract could be cross-linked to the viral RNA in vitro, suggesting that viral proteins may interact with viral RNA only indirectly through cellular proteins. Several cellular proteins have been shown to bind to the regulatory elements of MHV RNA, including the $5^{\prime}$ 
and $3^{\prime}$ ends of the genomic RNA and the $3^{\prime}$ end of the negative-strand RNA and IG sites. So far, only a handful of them have been identified, among which hnRNP A1 and PTB are the only two proteins found to interact with regions other than the $3^{\prime}$ end of the coronavirus genome. These proteins are likely to serve as mediators to bring the cis-regulatory regions together to form viral replication complexes. They may also help recruit and stabilize the RdRp to the initiation sites of viral RNA synthesis.

\section{1}

\section{HNRNP A1}

UV cross-linking experiments using cytoplasmic extracts of uninfected cells and the IG sequence showed that three different cellular proteins bind to IG of the template RNA (Zhang and Lai 1995a). Deletion analyses and site-directed mutagenesis of IG further demonstrated a correlation between protein binding and transcription efficiency, suggesting that these RNA-binding proteins are involved in the regulation of coronavirus mRNA transcription. One of these proteins was identified by partial peptide sequencing to be hnRNP Al (Li et al. 1997). hnRNP A1 is an RNA-binding protein that contains two RNA-binding domains (RBDs) and a glycine-rich domain responsible for protein-protein interaction. It is predominantly a nuclear protein but also shuttles between the nucleus and the cytoplasm (Pinol-Roma and Dreyfuss 1992). A 38-amino acid sequence, termed M9, located near the C terminus of hnRNP A1 between amino acids 268 and 305 has been determined to be the signal that mediates shuttling (Michael et al. 1995; Siomi and Dreyfuss 1995; Weighardt et al. 1995). The nuclear hnRNP A1 is known to be involved in pre-mRNA splicing and transport of cellular RNAs (Dreyfuss et al. 1993), whereas the cytoplasmic hnRNP A1 is capable of high-affinity binding to AU-rich elements and thus modulating mRNA turnover and translation (Hamilton et al. 1993, 1997; Henics et al. 1994). Another function of hnRNP A1 in the cytoplasm is to promote ribosome binding by a cap-mediated mechanism and to prevent spurious initiations at aberrant translation start sites (Svitkin et al. 1996).

hnRNP A1 binds MHV negative-strand leader and IG sequences (Furuya and Lai 1993; Li et al. 1997), which are critical elements for the discontinuous viral RNA transcription (Fig. 2). Site-directed mutagenesis of the IG sequences demonstrated that the extent of binding of hnRNP A1 to the IG sequences correlated with the efficiency of transcription from the IG site (Furuya and Lai 1993; Li et al. 1997; Zhang and Lai 


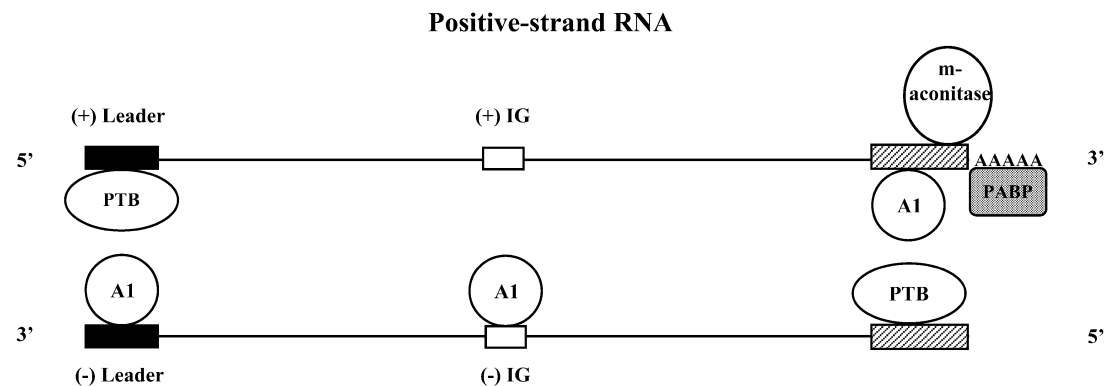

\section{Negative-strand RNA}

Fig. 2. Schematic drawings of the cellular proteins that interact with coronavirus RNA. hnRNP A1 interacts with the negative-strand leader and IG sequences as well as the positive-strand $3^{\prime}$-UTR, whereas PTB interacts with the positive-strand leader and the complementary sequence of $3^{\prime}$-UTR. These two proteins bind to sequences that are complementary to each other at both the $5^{\prime}$ and $3^{\prime}$ ends of coronavirus RNAs. The poly(A) tail and the $3^{\prime}$-most $42 \mathrm{nt}$ of the genomic RNA serve as binding domains for PABP and $\mathrm{m}$-aconitase, respectively

1995b). Immunostaining of hnRNP A1 showed that hnRNP A1 relocated to the cytoplasm of MHV-infected cells, where viral RNA synthesis occurs (Li et al. 1997). hnRNP A1 also interacts with the MHV N protein (Wang and Zhang 1999), which also binds to the MHV RNA directly (Baric et al. 1988; Stohlman et al. 1988). Furthermore, hnRNP A1 mediates the formation of a ribonucleoprotein complex containing the MHV negative-strand leader and IG sequences (Zhang et al. 1999), suggesting that it may serve as a protein mediator for distant RNA regions to interact with each other to form a transcription initiation complex. Remarkably, hnRNP A1 has also been shown to bind the positive-stranded $3^{\prime}$-UTR and may play a role in negative-strand RNA synthesis (Fig. 2) (Huang and Lai 2001).

The functional importance of hnRNP A1 in coronavirus RNA replication was shown in cells stably expressing the wild-type hnRNP A1 or a dominant-negative mutant of hnRNP A1, which lacks the C-terminal nuclear localization domain (Shi et al. 2000). Viral RNA synthesis was accelerated by the overexpression of hnRNP Al but delayed by the expression of the mutant hnRNP Al in the cytoplasm. Thus, the truncation mutant of hnRNP A1 interferes with viral RNA replication in a dominant-negative fashion. In addition to the general inhibition of viral RNA synthesis, the hnRNP A1 mutant also caused a preferential inhibition of 
the replication of DI RNAs, suggesting that the inhibition of MHV replication by the hnRNP A1 mutant was most likely a direct effect on viral RNA synthesis rather than an indirect effect on other aspects of cellular or viral functions. Because hnRNP A1 binds directly to the cis-acting MHV RNA sequences critical for MHV RNA transcription (Li et al. 1997) and replication (Huang and Lai 2001), it is most likely that hnRNP A1 may participate in the formation of the transcription/replication complex.

However, a mouse erythroleukemia cell line, CB3, that lacks detectable hnRNP A1 expression (Ben-David et al. 1992) can still support efficient MHV replication (Shen and Masters 2001). Because hnRNP Al protein is involved in a variety of important cellular functions, it is conceivable that other cellular gene products may substitute for the function of hnRNP A1 in both uninfected and virus-infected CB3 cells. Indeed, a number of CB3 cellular proteins comparable to hnRNP A1 in size were found to interact with the MHV negative-strand leader RNA. All of these proteins were identified to be hnRNP A1-related proteins, including hnRNP A/B, hnRNP A2/B1, and hnRNP A3 (Shi et al. 2003). These hnRNPs have primary sequence structure, biochemical properties, and function similar to those of hnRNP A1 (Dreyfuss et al. 1993; Ma et al. 2002; Mayeda et al. 1994). They also have binding specificity and affinity similar to MHV RNA compared with hnRNP A1 (Shi et al. 2003). One of these proteins, hnRNP A2/B1, can substitute for hnRNP A1 in regulating the splicing of cellular (Mayeda et al. 1994) and viral (Bilodeau et al. 2001; Caputi et al. 1999) pre-mRNAs. Together, these multiple hnRNP A1-related proteins may perform similar functions in MHV replication.

\section{2}

PTB

PTB, which is also known as hnRNP I, binds to the UC-rich RNA sequences typically found near the $3^{\prime}$ end of introns. Similar to hnRNP A1, PTB shuttles between the nucleus and cytoplasm and plays a role in the regulation of alternative splicing of pre-mRNAs and translation of cellular and viral RNAs (Kaminski et al. 1995; Svitkin et al. 1996; Valcarcel and Gebauer 1997). Studies of picornaviruses revealed that PTB plays a role in internal ribosome entry site (IRES)-mediated translation by mechanisms distinct from those governing the cap-dependent translation of most eukaryotic mRNAs (Jackson and Kaminski 1995). PTB was found to be associated with the IRES elements of encephalomyocarditis virus and foot-and-mouth-disease virus and to stimulate translation ini- 
tiated from these IRES elements (Kaminski et al. 1995; Niepmann 1996; Niepmann et al. 1997).

UV cross-linking and immunoprecipitation studies using cellular extracts and a recombinant PTB established that PTB binds specifically to the MHV positive-strand leader RNA (Fig. 2) (Li et al. 1999), which is required for MHV RNA synthesis (Kim et al. 1993; Liao and Lai 1994) and regulates translation (Tahara et al. 1994). The PTB-binding sites were mapped to the UCUAA pentanucleotide repeats within the leader RNA; deletion of these binding sites significantly inhibits RNA transcription (Li et al. 1999). Interestingly, PTB also interacts with the complementary strand of the $3^{\prime}$-UTR (c3'-UTR) (Fig. 2) (Huang and Lai 1999). A strong PTB-binding site was mapped to nt 53-149, and another weak binding site was mapped to nt $270-307$ on c3'-UTR. Partial substitutions of the PTB-binding nucleotides reduced PTB binding in vitro. Furthermore, DI RNAs harboring these mutations showed substantially reduced ability to synthesize subgenomic mRNA. Remarkably, the binding of PTB to nt 53-149 caused a conformational change in the neighboring RNA region. Partial deletions within the PTB-binding sequence completely abolished the PTB-induced conformational change in the mutant RNA even when the RNA retained partial PTB-binding activity. Correspondingly, the MHV DI RNAs containing these deletions lost their ability to transcribe mRNAs. Thus, the conformational change in the c3'-UTR caused by PTB binding may play a role in mRNA transcription.

It is interesting to note that hnRNP A1 and PTB bind to the precisely complementary sites on the negative- and positive-stranded RNA, respectively, of the leader region of MHV RNA, and also the $5^{\prime}$ - and $3^{\prime}$ ends of both the positive- and negative-strand RNAs (Fig. 2) (Huang and Lai 2001; Huang and Lai 1999; Li et al. 1997, 1999;). Furthermore, hnRNP A1 and PTB together mediate the formation of an RNP complex involving the $5^{\prime}$ - and $3^{\prime}$ end fragments of MHV RNA in vitro (Huang and Lai 2001). The interaction between hnRNP A1 and PTB have also been detected in a splicing complex in uninfected cells (Bothwell et al. 1991). All of these findings support the notion that hnRNP A1 and PTB may be involved in the formation of a ribonucleoprotein complex, which functions in MHV RNA synthesis.

Most coronavirus mRNAs are capped at the $5^{\prime}$ end and translated by a cap-dependent mechanism. The binding of PTB to the coronavirus leader RNA, which regulates MHV RNA translation (Tahara et al. 1994), suggests a possible role of PTB in coronavirus mRNA translation as well. Surprisingly, PTB was found to have no direct effect on the cap-dependent MHV RNA translation (Choi and Lai, unpublished data). It is, how- 
ever, still possible that PTB may affect the IRES-mediated translation of coronavirus ORF $5 \mathrm{~b}$, which encodes the envelope (E) protein (Lai and Cavanagh 1997; Thiel and Siddell 1994). The ORF 5b IRES has been shown to serve as a binding site for cellular proteins (Jendrach et al. 1999), although it is not known whether PTB is among these proteins.

\section{3}

\section{PABP}

The 3'-UTRs of coronavirus RNA are necessary for the synthesis of negative-strand viral RNA (Lin et al. 1994) and both genomic and subgenomic positive-strand RNA synthesis (Kim et al. 1993; Lin and Lai 1993; Lin et al. 1996). They contain structures that are conserved among divergent coronaviruses (Hsue et al. 2000; Hsue and Masters 1997; Liu et al. 2001). It is possible that these secondary structural elements serve as binding sites for cellular proteins and function in viral replication. Indeed, the mutations at the $3^{\prime}$ end of the viral genomic RNA that abolished the binding of cellular proteins also inhibited both negative-strand and positive-strand RNA synthesis, although the correlation between protein binding and RNA synthesis was not absolute (Liu et al. 1997; Yu and Leibowitz 1995a).

A number of cellular proteins have been found to interact with multiple sites within the $3^{\prime}$ end of positive-strand MHV RNA (Huang and Lai 2001; Liu et al. 1997; Spagnolo and Hogue 2000; Yu and Leibowitz 1995a, b). Several cellular proteins have also been shown to interact with the BCV 3'-UTR [287 nt plus poly(A) tail] (Huang and Lai 2001; Liu et al. 1997; Spagnolo and Hogue 2000; Yu and Leibowitz 1995a, b). Competition with the MHV $3^{\prime}$-UTR [301 nt plus poly(A) tail] suggests that the interactions are conserved for the two viruses (Huang and Lai 2001; Liu et al. 1997; Spagnolo and Hogue 2000; Yu and Leibowitz 1995a, b). Proteins with molecular masses of $99,95,73,40-50$, and $30 \mathrm{kDa}$ were detected, among which the 73-kDa protein was identified to be poly(A)binding protein (PABP) by immunoprecipitation experiments. PABP is known to interact specifically with poly(A), which is an important cisacting signal for coronavirus RNA replication (Fig. 2) (Lin et al. 1994). RNAs with shortened poly(A) tails exhibited less in vitro PABP binding. Furthermore, binding of PABP to the $3^{\prime}$-UTR of the DI RNA replicons correlated with the ability of the DI RNA to replicate, suggesting that the interaction between $\mathrm{PABP}$ and the poly(A) tail may affect coronavirus RNA replication (Huang and Lai 2001; Liu et al. 1997; Spagnolo and Hogue 2000; Yu and Leibowitz 1995a, b). 
PABP is a highly abundant cytoplasmic protein (Gorlach et al. 1994) that binds the $3^{\prime}$ poly(A) tail on eukaryotic mRNAs and helps promote both efficient translation initiation and mRNA stability. It interacts with the translation factor eukaryotic initiation factor (eIF) 4G (Imataka et al. 1998; Le et al. 1997; Tarun and Sachs 1996; Tarun et al. 1997), which is part of the eIF4F triple complex that binds mRNA cap structures during translation, and PABP-interacting protein (PAIP-1), a protein with homology to eIF-4G (Craig et al. 1998). This interaction, known as the closed-loop model of translation initiation, mediates the cross talk between the $5^{\prime}$ and $3^{\prime}$ ends of mRNAs (Gallie 1998; Sachs et al. 1997). Because coronavirus RNA is capped and polyadenylated like the host mRNAs, PABP is likely involved in the translation of the coronavirus genome upon virus entry into the cell. Because translation is required for efficient coronavirus RNA replication, it is conceivable that PABP can indirectly modulate RNA synthesis through its effect on translation. It is also possible that the PABP-poly(A) interaction may play a more direct role in coronavirus RNA replication in view of the apparent requirement for both the $5^{\prime}$ and $3^{\prime}$ ends, including the poly(A) tail, of the coronavirus genome for DI RNA replication and mRNA transcription (Kim et al. 1993; Lai 1998; Liao and Lai 1994; Lin et al. 1994, 1996). Indeed, hnRNP A1 and PTB together have been shown to mediate the interaction between the $5^{\prime}$ and $3^{\prime}$ ends of MHV RNA (Huang and Lai 2001). PABP may be another cellular factor that facilitates a similar interaction of the ends.

\section{4}

\section{Mitochondrial Aconitase}

The 3'-most $42 \mathrm{nt}$ of the MHV genomic RNA has been shown to interact with host factors and form at least three RNA-protein complexes (Nanda and Leibowitz 2001). Four proteins of approximately 90, 70, 58, and $40 \mathrm{kDa}$ were resolved from these complexes, and the $90-\mathrm{kDa}$ protein was identified as mitochondrial aconitase ( $\mathrm{m}$-aconitase), which catalyzes stereospecific interconversion of citrate into isocitrate through a cis-aconitase intermediate in the Krebs cycle (Beinert and Kennedy 1993). UV cross-linking studies indicate that the highly purified $\mathrm{m}$-aconitase binds specifically to the MHV $3^{\prime}$ protein-binding element despite the absence of a consensus RNA-binding domain (Fig. 2) (Burd and Dreyfuss 1994). Colocalization of $\mathrm{m}$-aconitase with the MHV $\mathrm{N}$ protein was observed in virus-infected cells, suggesting a possible interaction of $\mathrm{m}$-aconitase with the MHV replication complexes (Nanda and Leibowitz 2001). 
A cytoplasmic homolog of m-aconitase, cytoplasmic aconitase (c-aconitase), also known as iron regulatory protein 1, is a well-recognized RNA-binding protein (Kennedy et al. 1992). The binding properties of $\mathrm{m}$-aconitase and the functional relevance of RNA binding appear to parallel those of c-aconitase. c-Aconitase is a bifunctional protein, which has been shown to interact with iron-responsive elements located in the $5^{\prime}$-UTR of ferritin mRNA and the $3^{\prime}$-UTR of transferrin receptor (TfR) mRNA and to function to coordinate posttranscriptional regulation of cellular iron metabolism (Hentze and Kuhn 1996; Kuhn and Hentze 1992). Similarly, m-aconitase can function as a posttranscriptional regulator as well (Beinert and Kennedy 1993; Klausner et al. 1993). A link between cellular iron status and $\mathrm{m}$-aconitase expression has also been established (Kim et al. 1996; Schalinske et al. 1998). Increasing the intracellular level of m-aconitase of MHV-infected cells by iron supplementation resulted in increased RNA-binding activity of cell extracts and increased virus production as well as viral protein synthesis at early hours of infection (Nanda and Leibowitz 2001). It is possible that the binding of m-aconitase to the 3 -UTR increases the stability of the viral mRNAs and hence augments the translation of viral proteins, similar to the role of IRP in regulating TfR (Kuhn and Hentze 1992).

\section{5}

\section{Other Cellular Proteins}

Accumulating evidence indicates the presence of additional cellular proteins that interact with coronavirus RNA. The $3^{\prime}$-UTRs of murine and bovine coronaviruses were reported to contain bulged stem-loop (Hsue et al. 2000; Hsue and Masters 1997) and pseudoknot (Williams et al. 1995) structures, which are essential for viral replication. These motifs are potential binding sites for the proteins shown to interact with the $3^{\prime}$ UTR. Indeed, a number of cellular proteins have been shown to interact with different regions within the $3^{\prime}$-UTR of MHV (Liu et al. 1997; Nanda and Leibowitz 2001; Yu and Leibowitz 1995a, b). The 3'-most 42-nt sequence interacts with at least four proteins $90,70,58$, and $40 \mathrm{kDa}$ in size, among which the $90-\mathrm{kDa}$ protein was identified as m-aconitase (Nanda and Leibowitz 2001). A distinct host cellular protein-binding element was also mapped within a 26-nt sequence at positions 154-129 from the $3^{\prime}$ end of the MHV-JHM genome (Liu et al. 1997). The resulting RNAprotein complex contains six host cellular proteins with one protein of $120-\mathrm{kDa}$ molecular mass, two poorly resolved species approximately $55 \mathrm{kDa}$ in size, a second pair of poorly resolved $40-\mathrm{kDa}$ proteins, and a 
minor component of $25 \mathrm{kDa}$. This region contains multiple stem-loop and hairpin-loop structures, which are shown by mutational analysis to be important for efficient MHV replication (Liu et al. 2001). In the study that identified PABP, several other proteins with molecular masses of 99, $95,40-50$, and $30 \mathrm{kDa}$ were also shown to interact with the $3^{\prime}$-UTRs of both BCV and MHV (Spagnolo and Hogue 2000). These cellular proteins have the potential to regulate viral RNA synthesis through their binding to the $3^{\prime}$ ends of the coronavirus genomes; however, their identities and functions remain to be determined.

\section{6}

\section{Proposed Functions of Cellular Proteins}

The cis-acting signals for viral RNA replication or transcription often consist of multiple distant sequences on the viral RNA. In many cases, there appears to be a cross talk between the $5^{\prime}$ and $3^{\prime}$ ends of viral RNAs so that the $3^{\prime}$ end sequence often can regulate RNA synthesis or translation initiated from the $5^{\prime}$ end of the RNA. The $5^{\prime}$ - and $3^{\prime}$-UTRs of both positive- and negative-sense RNA and the IG sequences are thought to contain important sequence and structural elements that function in the initiation and regulation of RNA replication, transcription, and translation. The $3^{\prime}$ end of the MHV RNA has been shown to regulate mRNA synthesis starting from an upstream internal promoter (Lin et al. 1996). The poly(A) tail is also involved in coronavirus RNA synthesis (Huang and Lai 2001; Liu et al. 1997; Spagnolo and Hogue 2000; Yu and Leibowitz 1995a, b). Furthermore, there is an apparent interaction between the leader and IG sequences, which regulates the synthesis of coronavirus subgenomic mRNAs (Lai and Cavanagh 1997; Zhang et al. 1994). When no sequence complementarity exists between the $5^{\prime}$ and $3^{\prime}$ ends, RNA-protein and protein-protein interactions must be involved. hnRNP A1 and PTB have the ability to interact with each other, thus allowing different RNA regions to interact (Fig. 3A). By analogy to translation regulation, the binding of PABP to the $3^{\prime}$ end of the coronavirus genome may also facilitate the cross talk between the $3^{\prime}$ end and the other upstream cis-acting sequences. Furthermore, because most of the viral RdRps do not appear to bind directly to the cis-acting regulatory or promoter sequences on the RNA, their ability to initiate RNA synthesis at specific sites probably depends on their interactions with the cellular proteins that bind directly to the viral RNA template. These cellular proteins may serve as a platform on which other proteins, both viral and 
A

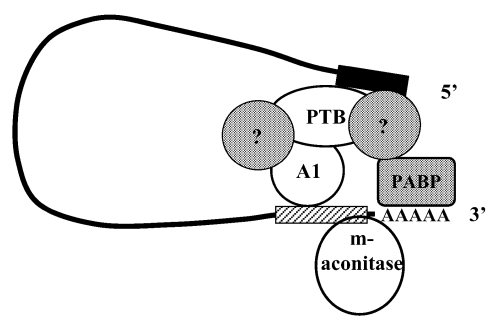

B

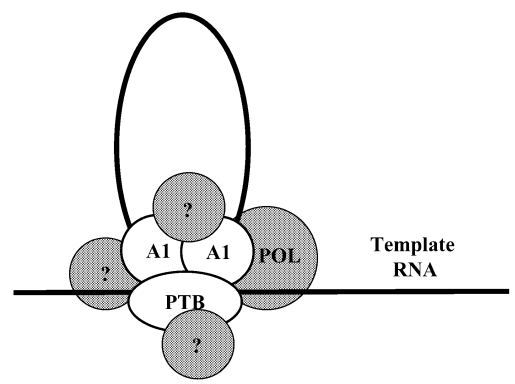

Fig. 3A, B. Proposed functions of cellular proteins in coronavirus replication. A Interactions between distant RNA elements are mediated by hnRNP A1, PTB, and PABP. B Formation of coronavirus replication/transcription complexes through the recruitment of additional viral and cellular proteins by hnRNP Al and PTB

cellular, subsequently bind to form functional replication and transcription complexes (Fig. 3B).

Together, cellular proteins play important roles in coronavirus replication. Identification of these proteins and analysis of their functions in virus replication are critical to furthering our understanding of virushost interactions and will provide clues to unveil the replication strategies of other positive-stranded RNA viruses.

\section{4}

\section{Perspectives}

Although an increasing body of literature supports the importance of various viral and cellular proteins in coronavirus replication, our current understanding of the roles of these proteins is still limited. The availability of the reverse genetics approach for coronaviruses is expected to greatly accelerate the understanding of coronavirus replication as well as the functional importance of viral and cellular factors in coronavirus replication. In addition, the growing knowledge of the properties of the individual protein products of the coronavirus ORF 1 should help in understanding the makeup of the replication machinery. The recent advances in gene knockout by RNA interference (RNAi) in mammalian cells will likely be a valuable tool in establishing the functional relevance of these cellular proteins. Nevertheless, the ultimate unraveling of the viral and cellular proteins involved in coronavirus replication is expected 
to come after the purification of coronavirus $\mathrm{RdRp}$ and the reconstitution of virus replication in vitro.

\section{References}

Ahola T, den Boon JA, Ahlquist P (2000) Helicase and capping enzyme active site mutations in brome mosaic virus protein 1a cause defects in template recruitment, negative-strand RNA synthesis, and viral RNA capping. J Virol 74:88038811

Baker SC, Lai MM (1990) An in vitro system for the leader-primed transcription of coronavirus mRNAs. EMBO J 9:4173-4179

Baker SC, Shieh CK, Soe LH, Chang MF, Vannier DM, Lai MM (1989) Identification of a domain required for autoproteolytic cleavage of murine coronavirus gene $\mathrm{A}$ polyprotein. J Virol 63:3693-3699

Baker SC, Yokomori K, Dong S, Carlisle R, Gorbalenya AE, Koonin EV, Lai MM (1993) Identification of the catalytic sites of a papain-like cysteine proteinase of murine coronavirus. J Virol 67:6056-6063

Baker TA, Bell SP (1998) Polymerases and the replisome: machines within machines. Cell 92:295-305

Baric RS, Fu K, Schaad MC, Stohlman SA (1990a) Establishing a genetic recombination map for murine coronavirus strain A59 complementation groups. Virology 177:646-656

Baric RS, Nelson GW, Fleming JO, Deans RJ, Keck JG, Casteel N, Stohlman SA (1988) Interactions between coronavirus nucleocapsid protein and viral RNAs: implications for viral transcription. J Virol 62:4280-4287

Baric RS, Schaad MC, Wei T, Fu KS, Lum K, Shieh C, Stohlman SA (1990b) Murine coronavirus temperature sensitive mutants. Adv Exp Med Biol 276:349-356

Behrens SE, Tomei L, De Francesco R (1996) Identification and properties of the RNA-dependent RNA polymerase of hepatitis C virus. EMBO J 15:12-22

Beinert H, Kennedy MC (1993) Aconitase, a two-faced protein: enzyme and iron regulatory factor. FASEB J 7:1442-1449

Ben-David Y, Bani MR, Chabot B, De Koven A, Bernstein A (1992) Retroviral insertions downstream of the heterogeneous nuclear ribonucleoprotein A1 gene in erythroleukemia cells: evidence that A1 is not essential for cell growth. Mol Cell Biol 12:4449-4455

Bienz K, Egger D, Pfister T (1994) Characteristics of the poliovirus replication complex. Arch Virol Suppl 9:147-157

Bilodeau PS, Domsic JK, Mayeda A, Krainer AR, Stoltzfus CM (2001) RNA splicing at human immunodeficiency virus type $13^{\prime}$ splice site A2 is regulated by binding of hnRNP A/B proteins to an exonic splicing silencer element. J Virol 75:84878497

Black AC, Luo J, Chun S, Bakker A, Fraser JK, Rosenblatt JD (1996) Specific binding of polypyrimidine tract binding protein and hnRNP A1 to HIV-1 CRS elements. Virus Genes 12:275-285 
Black AC, Luo J, Watanabe C, Chun S, Bakker A, Fraser JK, Morgan JP, Rosenblatt JD (1995) Polypyrimidine tract-binding protein and heterogeneous nuclear ribonucleoprotein A1 bind to human T-cell leukemia virus type 2 RNA regulatory elements. J Virol 69:6852-6858

Blackwell JL, Brinton MA (1997) Translation elongation factor-1 alpha interacts with the $3^{\prime}$ stem-loop region of West Nile virus genomic RNA. J Virol 71:6433-6444

Blumenthal T, Carmichael GG (1979) RNA replication: function and structure of Qbeta-replicase. Annu Rev Biochem 48:525-548

Bonilla PJ, Gorbalenya AE, Weiss SR (1994) Mouse hepatitis virus strain A59 RNA polymerase gene ORF 1a: heterogeneity among MHV strains. Virology 198:736740

Bonilla PJ, Hughes SA, Pinon JD, Weiss SR (1995) Characterization of the leader papain-like proteinase of MHV-A59: identification of a new in vitro cleavage site. Virology 209:489-497

Bonilla PJ, Hughes SA, Weiss SR (1997) Characterization of a second cleavage site and demonstration of activity in trans by the papain-like proteinase of the murine coronavirus mouse hepatitis virus strain A59. J Virol 71:900-909

Bost AG, Carnahan RH, Lu XT, Denison MR (2000) Four proteins processed from the replicase gene polyprotein of mouse hepatitis virus colocalize in the cell periphery and adjacent to sites of virion assembly. J Virol 74:3379-3387

Bost AG, Prentice E, Denison MR (2001) Mouse hepatitis virus replicase protein complexes are translocated to sites of $M$ protein accumulation in the ERGIC at late times of infection. Virology 285:21-29

Bothwell AL, Ballard DW, Philbrick WM, Lindwall G, Maher SE, Bridgett MM, Jamison SF, Garcia-Blanco MA (1991) Murine polypyrimidine tract binding protein. Purification, cloning, and mapping of the RNA binding domain. J Biol Chem 266:24657-24663

Brayton PR, Lai MM, Patton CD, Stohlman SA (1982) Characterization of two RNA polymerase activities induced by mouse hepatitis virus. J Virol 42:847-853

Brayton PR, Stohlman SA, Lai MM (1984) Further characterization of mouse hepatitis virus RNA-dependent RNA polymerases. Virology 133:197-201

Bredenbeek PJ, Pachuk CJ, Noten AF, Charite J, Luytjes W, Weiss SR, Spaan WJ (1990) The primary structure and expression of the second open reading frame of the polymerase gene of the coronavirus MHV-A59; a highly conserved polymerase is expressed by an efficient ribosomal frameshifting mechanism. Nucleic Acids Res 18:1825-1832

Brierley I, Boursnell ME, Binns MM, Bilimoria B, Blok VC, Brown TD, Inglis SC (1987) An efficient ribosomal frame-shifting signal in the polymerase-encoding region of the coronavirus IBV. EMBO J 6:3779-3785

Buck KW (1996) Comparison of the replication of positive-stranded RNA viruses of plants and animals. Adv Virus Res 47:159-251

Burd CG, Dreyfuss G (1994) Conserved structures and diversity of functions of RNA-binding proteins. Science 265:615-621

Caputi M, Mayeda A, Krainer AR, Zahler AM (1999) hnRNP A/B proteins are required for inhibition of HIV-1 pre-mRNA splicing. EMBO J 18:4060-4067

Caputi M, Zahler AM (2002) SR proteins and hnRNP H regulate the splicing of the HIV-1 tev-specific exon 6D. EMBO J 21:845-855 
Chambers TJ, Hahn CS, Galler R, Rice CM (1990) Flavivirus genome organization, expression, and replication. Annu Rev Microbiol 44:649-688

Chang RY, Brian DA (1996) cis Requirement for N-specific protein sequence in bovine coronavirus defective interfering RNA replication. J Virol 70:2201-2207

Chang RY, Hofmann MA, Sethna PB, Brian DA (1994) A cis-acting function for the coronavirus leader in defective interfering RNA replication. J Virol 68:8223-8231

Chung RT, Kaplan LM (1999) Heterogeneous nuclear ribonucleoprotein I (hnRNP-I/ PTB) selectively binds the conserved $3^{\prime}$ terminus of hepatitis $C$ viral RNA. Biochem Biophys Res Commun 254:351-362

Cologna R, Spagnolo JF, Hogue BG (2000) Identification of nucleocapsid binding sites within coronavirus-defective genomes. Virology 277:235-249

Compton SR, Rogers DB, Holmes KV, Fertsch D, Remenick J, McGowan JJ (1987) In vitro replication of mouse hepatitis virus strain A59. J Virol 61:1814-1820

Craig AW, Haghighat A, Yu AT, Sonenberg N (1998) Interaction of polyadenylatebinding protein with the eIF4G homologue PAIP enhances translation. Nature 392:520-523

Das T, Mathur M, Gupta AK, Janssen GM, Banerjee AK (1998) RNA polymerase of vesicular stomatitis virus specifically associates with translation elongation factor- $1 \alpha \beta \gamma$ for its activity. Proc Natl Acad Sci USA 95:1449-1454

De BP, Lesoon A, Banerjee AK (1991) Human parainfluenza virus type 3 transcription in vitro: role of cellular actin in mRNA synthesis. J Virol 65:3268-3275

de la Cruz J, Kressler D, Linder P (1999) Unwinding RNA in Saccharomyces cerevisiae: DEAD-box proteins and related families. Trends Biochem Sci 24:192-198

Denison M, Perlman S (1987) Identification of putative polymerase gene product in cells infected with murine coronavirus A59. Virology 157:565-568

Denison MR, Hughes SA, Weiss SR (1995a) Identification and characterization of a $65-\mathrm{kDa}$ protein processed from the gene 1 polyprotein of the murine coronavirus MHV-A59. Virology 207:316-320

Denison MR, Kim JC, Ross T (1995b) Inhibition of coronavirus MHV-A59 replication by proteinase inhibitors. Adv Exp Med Biol 380:391-397

Denison MR, Spaan WJ, van der Meer Y, Gibson CA, Sims AC, Prentice E, Lu XT (1999) The putative helicase of the coronavirus mouse hepatitis virus is processed from the replicase gene polyprotein and localizes in complexes that are active in viral RNA synthesis. J Virol 73:6862-6871

Denison MR, Zoltick PW, Hughes SA, Giangreco B, Olson AL, Perlman S, Leibowitz JL, Weiss SR (1992) Intracellular processing of the N-terminal ORF 1a proteins of the coronavirus MHV-A59 requires multiple proteolytic events. Virology 189:274-284

Dennis DE, Brian DA (1982) RNA-dependent RNA polymerase activity in coronavirus-infected cells. J Virol 42:153-164

Diez J, Ishikawa M, Kaido M, Ahlquist P (2000) Identification and characterization of a host protein required for efficient template selection in viral RNA replication. Proc Natl Acad Sci USA 97:3913-3918

Dong S, Baker SC (1994) Determinants of the p28 cleavage site recognized by the first papain-like cysteine proteinase of murine coronavirus. Virology 204:541549 
Dreyfuss G, Matunis MJ, Pinol-Roma S, Burd CG (1993) hnRNP proteins and the biogenesis of mRNA. Annu Rev Biochem 62:289-321

Froshauer S, Kartenbeck J, Helenius A (1988) Alphavirus RNA replicase is located on the cytoplasmic surface of endosomes and lysosomes. J Cell Biol 107:20752086

Fu K, Baric RS (1994) Map locations of mouse hepatitis virus temperature-sensitive mutants: confirmation of variable rates of recombination. J Virol 68:7458-7466

Furuya T, Lai MMC (1993) Three different cellular proteins bind to complementary sites on the $5^{\prime}$-end-positive and $3^{\prime}$ end-negative strands of mouse hepatitis virus RNA. J Virol 67:7215-7222

Gallie DR (1998) A tale of two termini: a functional interaction between the termini of an mRNA is a prerequisite for efficient translation initiation. Gene 216:1-11

Gamarnik AV, Andino R (1997) Two functional complexes formed by KH domain containing proteins with the $5^{\prime}$ noncoding region of poliovirus RNA. RNA 3:882892

Gamarnik AV, Andino R (1998) Switch from translation to RNA replication in a positive-stranded RNA virus. Genes Dev 12:2293-2304

Gao HQ, Schiller JJ, Baker SC (1996) Identification of the polymerase polyprotein products p72 and p65 of the murine coronavirus MHV-JHM. Virus Res 45:101109

Gontarek RR, Gutshall LL, Herold KM, Tsai J, Sathe GM, Mao J, Prescott C, Del Vecchio AM (1999) hnRNP C and polypyrimidine tract-binding protein specifically interact with the pyrimidine-rich region within the $3^{\prime} \mathrm{NTR}$ of the HCV RNA genome. Nucleic Acids Res 27:1457-1463

Gorbalenya AE, Blinov VM, Donchenko AP, Koonin EV (1989a) An NTP-binding motif is the most conserved sequence in a highly diverged monophyletic group of proteins involved in positive strand RNA viral replication. J Mol Evol 28:256268

Gorbalenya AE, Koonin EV (1989) Viral proteins containing the purine NTP-binding sequence pattern. Nucleic Acids Res 17:8413-8440

Gorbalenya AE, Koonin EV (1993) Helicases: amino acid comparisons and structure-function relationships. Curr Opin Struct Biol 3:419-429

Gorbalenya AE, Koonin EV, Donchenko AP, Blinov VM (1988) A novel superfamily of nucleoside triphosphate-binding motif containing proteins which are probably involved in duplex unwinding in DNA and RNA replication and recombination. FEBS Lett 235:16-24

Gorbalenya AE, Koonin EV, Donchenko AP, Blinov VM (1989b) Coronavirus genome: prediction of putative functional domains in the non-structural polyprotein by comparative amino acid sequence analysis. Nucleic Acids Res 17:48474861

Gorbalenya AE, Koonin EV, Lai MM (1991) Putative papain-related thiol proteases of positive-strand RNA viruses. Identification of rubi- and aphthovirus proteases and delineation of a novel conserved domain associated with proteases of rubi-, alpha- and coronaviruses. FEBS Lett 288:201-205

Gorlach M, Burd CG, Dreyfuss G (1994) The mRNA poly(A)-binding protein: localization, abundance, and RNA-binding specificity. Exp Cell Res 211:400-407 
Grotzinger C, Heusipp G, Ziebuhr J, Harms U, Suss J, Siddell SG (1996) Characterization of a $105-\mathrm{kDa}$ polypeptide encoded in gene 1 of the human coronavirus HCV 229E. Virology 222:227-235

Gutierrez-Escolano AL, Brito ZU, del Angel RM, Jiang X (2000) Interaction of cellular proteins with the $5^{\prime}$ end of Norwalk virus genomic RNA. J Virol 74:8558-8562

Hahm B, Kim YK, Kim JH, Kim TY, Jang SK (1998) Heterogeneous nuclear ribonucleoprotein L interacts with the $3^{\prime}$ border of the internal ribosomal entry site of hepatitis C virus. J Virol 72:8782-8788

Hamilton BJ, Burns CM, Nichols RC, Rigby WFC (1997) Modulation of AUUUA response element binding by heterogeneous nuclear ribonucleoprotein A1 in human T lymphocytes. The roles of cytoplasmic location, transcription, and phosphorylation. J Biol Chem 272:28732-28741

Hamilton BJ, Nagy E, Malter JS, Arrick BA, Rigby WFC (1993) Association of heterogeneous nuclear ribonucleoprotein $\mathrm{A} 1$ and $\mathrm{C}$ proteins with reiterated AUUUA sequences. J Biol Chem 268:8881-8887

Harris KS, Xiang W, Alexander L, Lane WS, Paul AV, Wimmer E (1994) Interaction of poliovirus polypeptide $3 \mathrm{CD}$ pro with the $5^{\prime}$ and $3^{\prime}$ termini of the poliovirus genome. Identification of viral and cellular cofactors needed for efficient binding. J Biol Chem 269:27004-27014

Hellen CU, Pestova TV, Litterst M, Wimmer E (1994) The cellular polypeptide p57 (pyrimidine tract-binding protein) binds to multiple sites in the poliovirus $5^{\prime}$ nontranslated region. J Virol 68:941-950

Henics T, Sanfridson A, Hamilton BJ, Nagy E, Rigby WFC (1994) Enhanced stability of interleukin-2 mRNA in MLA 144 cells. Possible role of cytoplasmic AU-rich sequence-binding proteins. J Biol Chem 269:5377-5383

Hentze MW, Kuhn LC (1996) Molecular control of vertebrate iron metabolism: mRNA-based regulatory circuits operated by iron, nitric oxide, and oxidative stress. Proc Natl Acad Sci USA 93:8175-8182

Herold J, Gorbalenya AE, Thiel V, Schelle B, Siddell SG (1998) Proteolytic processing at the amino terminus of human coronavirus 229E gene 1-encoded polyproteins: identification of a papain-like proteinase and its substrate. J Virol 72:910-918

Herold J, Siddell SG (1993) An 'elaborated' pseudoknot is required for high frequency frameshifting during translation of HCV 229E polymerase mRNA. Nucleic Acids Res 21:5838-5842

Herold J, Siddell SG, Gorbalenya AE (1999) A human RNA viral cysteine proteinase that depends upon a unique $\mathrm{Zn}^{2+}$-binding finger connecting the two domains of a papain-like fold. J Biol Chem 274:14918-14925

Hong Y, Hunt AG (1996) RNA polymerase activity catalyzed by a potyvirus-encoded RNA-dependent RNA polymerase. Virology 226:146-151

Hsue B, Hartshorne T, Masters PS (2000) Characterization of an essential RNA secondary structure in the $3^{\prime}$ untranslated region of the murine coronavirus genome. J Virol 74:6911-6921

Hsue B, Masters PS (1997) A bulged stem-loop structure in the $3^{\prime}$ untranslated region of the genome of the coronavirus mouse hepatitis virus is essential for replication. J Virol 71:7567-7578 
Huang P, Lai MM (2001) Heterogeneous nuclear ribonucleoprotein al binds to the $3^{\prime}$-untranslated region and mediates potential $5^{\prime}-3^{\prime}$ end cross talks of mouse hepatitis virus RNA. J Virol 75:5009-5017

Huang P, Lai MMC (1999) Polypyrimidine tract-binding protein binds to the complementary strand of the mouse hepatitis virus $3^{\prime}$ untranslated region, thereby altering RNA conformation. J Virol 73:9110-9116

Huang YT, Romito RR, De BP, Banerjee AK (1993) Characterization of the in vitro system for the synthesis of mRNA from human respiratory syncytial virus. Virology 193:862-867

Hughes SA, Bonilla PJ, Weiss SR (1995) Identification of the murine coronavirus p28 cleavage site. J Virol 69:809-813

Imataka H, Gradi A, Sonenberg N (1998) A newly identified N-terminal amino acid sequence of human eIF4G binds poly(A)-binding protein and functions in poly(A)-dependent translation. EMBO J 17:7480-7489

Ito T, Lai MMC (1997) Determination of the secondary structure of and cellular protein binding to the $3^{\prime}$-untranslated region of the hepatitis $C$ virus RNA genome. J Virol 71:8698-8706

Jackson RJ, Kaminski A (1995) Internal initiation of translation in eukaryotes: the picornavirus paradigm and beyond. RNA 1:985-1000

Jankowsky E, Gross CH, Shuman S, Pyle AM (2000) The DExH protein NPH-II is a processive and directional motor for unwinding RNA. Nature 403:447-451

Jendrach M, Thiel V, Siddell S (1999) Characterization of an internal ribosome entry site within mRNA 5 of murine hepatitis virus. Arch Virol 144:921-933

Joshi RL, Ravel JM, Haenni AL (1986) Interaction of turnip yellow mosaic virus ValRNA with eukaryotic elongation factor EF-1 $\alpha$. Search for a function. EMBO J 5:1143-1148

Kadare G, Haenni AL (1997) Virus-encoded RNA helicases. J Virol 71:2583-2590

Kaminski A, Hunt SL, Patton JG, Jackson RJ (1995) Direct evidence that polypyrimidine tract binding protein (PTB) is essential for internal initiation of translation of encephalomyocarditis virus RNA. RNA 1:924-938

Kanjanahaluethai A, Baker SC (2000) Identification of mouse hepatitis virus papainlike proteinase 2 activity. J Virol 74:7911-7921

Kennedy MC, Mende-Mueller L, Blondin GA, Beinert H (1992) Purification and characterization of cytosolic aconitase from beef liver and its relationship to the iron-responsive element binding protein. Proc Natl Acad Sci USA 89:1173011734

Kim HY, LaVaute T, Iwai K, Klausner RD, Rouault TA (1996) Identification of a conserved and functional iron-responsive element in the $5^{\prime}$-untranslated region of mammalian mitochondrial aconitase. J Biol Chem 271:24226-24230

Kim JC, Spence RA, Currier PF, Lu X, Denison MR (1995) Coronavirus protein processing and RNA synthesis is inhibited by the cysteine proteinase inhibitor E64d. Virology 208:1-8

Kim KH, Makino S (1995a) Two murine coronavirus genes suffice for viral RNA synthesis. J Virol 69:2313-2321

Kim YN, Jeong YS, Makino S (1993) Analysis of cis-acting sequences essential for coronavirus defective interfering RNA replication. Virology 197:53-63 
Kim YN, Makino S (1995b) Characterization of a murine coronavirus defective interfering RNA internal cis-acting replication signal. J Virol 69:4963-4971

Klausner RD, Rouault TA, Harford JB (1993) Regulating the fate of mRNA: the control of cellular iron metabolism. Cell 72:19-28

Koolen MJ, Osterhaus AD, Van Steenis G, Horzinek MC, Van der Zeijst BA (1983) Temperature-sensitive mutants of mouse hepatitis virus strain A59: isolation, characterization and neuropathogenic properties. Virology 125:393-402

Koonin EV, Dolja VV (1993) Evolution and taxonomy of positive-strand RNA viruses: implications of comparative analysis of amino acid sequences. Crit Rev Biochem Mol Biol 28:375-430

Kuhn LC, Hentze MW (1992) Coordination of cellular iron metabolism by post-transcriptional gene regulation. J Inorg Biochem 47:183-195

Lai MMC (1998) Cellular factors in the transcription and replication of viral RNA genomes: a parallel to DNA-dependent RNA transcription. Virology 244:1-12

Lai MMC, Cavanagh D (1997) The molecular biology of coronaviruses. Adv Virus Res 48:1-100

Landers TA, Blumenthal T, Weber K (1974) Function and structure in ribonucleic acid phage $\mathrm{Q}$ beta ribonucleic acid replicase. The roles of the different subunits in transcription of synthetic templates. J Biol Chem 249:5801-5808

Le H, Tanguay RL, Balasta ML, Wei CC, Browning KS, Metz AM, Goss DJ, Gallie DR (1997) Translation initiation factors eIF-iso4G and eIF-4B interact with the poly(A)-binding protein and increase its RNA binding activity. J Biol Chem 272:16247-16255

Lee HJ, Shieh CK, Gorbalenya AE, Koonin EV, La Monica N, Tuler J, Bagdzhadzhyan A, Lai MM (1991) The complete sequence (22 kilobases) of murine coronavirus gene 1 encoding the putative proteases and RNA polymerase. Virology 180:567582

Leibowitz JL, DeVries JR (1988) Synthesis of virus-specific RNA in permeabilized murine coronavirus-infected cells. Virology 166:66-75

Leibowitz JL, DeVries JR, Haspel MV (1982) Genetic analysis of murine hepatitis virus strain JHM. J Virol 42:1080-1087

Li HP, Huang P, Park S, Lai MMC (1999) Polypyrimidine tract-binding protein binds to the leader RNA of mouse hepatitis virus and serves as a regulator of viral transcription. J Virol 73:772-777

Li HP, Zhang X, Duncan R, Comai L, Lai MMC (1997) Heterogeneous nuclear ribonucleoprotein A1 binds to the transcription-regulatory region of mouse hepatitis virus RNA. Proc Natl Acad Sci USA 94:9544-9549

Liao CL, Lai MMC (1994) Requirement of the $5^{\prime}$ end genomic sequence as an upstream cis-acting element for coronavirus subgenomic mRNA transcription. J Virol 68:4727-4737

Lim KP, Liu DX (1998) Characterization of the two overlapping papain-like proteinase domains encoded in gene 1 of the coronavirus infectious bronchitis virus and determination of the C-terminal cleavage site of an $87-\mathrm{kDa}$ protein. Virology 245:303-312

Lim KP, Ng LF, Liu DX (2000) Identification of a novel cleavage activity of the first papain-like proteinase domain encoded by open reading frame 1a of the corona- 
virus avian infectious bronchitis virus and characterization of the cleavage products. J Virol 74:1674-1685

Lin YJ, Lai MM (1993) Deletion mapping of a mouse hepatitis virus defective interfering RNA reveals the requirement of an internal and discontiguous sequence for replication. J Virol 67:6110-6118

Lin YJ, Liao CL, Lai MM (1994) Identification of the cis-acting signal for minusstrand RNA synthesis of a murine coronavirus: implications for the role of minus-strand RNA in RNA replication and transcription. J Virol 68:8131-8140

Lin YJ, Zhang X, Wu RC, Lai MMC (1996) The $3^{\prime}$ untranslated region of coronavirus RNA is required for subgenomic mRNA transcription from a defective interfering RNA. J Virol 70:7236-7240

Linder P, Daugeron MC (2000) Are DEAD-box proteins becoming respectable helicases? Nat Struct Biol 7:97-99

Liu DX, Brierley I, Tibbles KW, Brown TD (1994) A 100-kilodalton polypeptide encoded by open reading frame (ORF) $1 \mathrm{~b}$ of the coronavirus infectious bronchitis virus is processed by ORF 1a products. J Virol 68:5772-5780

Liu DX, Brown TD (1995) Characterisation and mutational analysis of an ORF 1aencoding proteinase domain responsible for proteolytic processing of the infectious bronchitis virus 1a/1b polyprotein. Virology 209:420-427

Liu DX, Shen S, Xu HY, Wang SF (1998) Proteolytic mapping of the coronavirus infectious bronchitis virus $1 \mathrm{~b}$ polyprotein: evidence for the presence of four cleavage sites of the 3C-like proteinase and identification of two novel cleavage products. Virology 246:288-297

Liu Q, Johnson RF, Leibowitz JL (2001) Secondary structural elements within the $3^{\prime}$ untranslated region of mouse hepatitis virus strain JHM genomic RNA. J Virol 75:12105-12113

Liu Q, Yu W, Leibowitz JL (1997) A specific host cellular protein binding element near the $3^{\prime}$ end of mouse hepatitis virus genomic RNA. Virology 232:74-85

Lohman TM, Bjornson KP (1996) Mechanisms of helicase-catalyzed DNA unwinding. Annu Rev Biochem 65:169-214

Lohmann V, Korner F, Herian U, Bartenschlager R (1997) Biochemical properties of hepatitis C virus NS5B RNA-dependent RNA polymerase and identification of amino acid sequence motifs essential for enzymatic activity. J Virol 71:84168428

Lu X, Lu Y, Denison MR (1996) Intracellular and in vitro-translated 27-kDa proteins contain the 3C-like proteinase activity of the coronavirus MHV-A59. Virology 222:375-382

Lu XT, Sims AC, Denison MR (1998) Mouse hepatitis virus 3C-like protease cleaves a 22 -kilodalton protein from the open reading frame 1a polyprotein in virus-infected cells and in vitro. J Virol 72:2265-2271

Lu Y, Denison MR (1997) Determinants of mouse hepatitis virus 3C-like proteinase activity. Virology 230:335-342

Lu Y, Lu X, Denison MR (1995) Identification and characterization of a serine-like proteinase of the murine coronavirus MHV-A59. J Virol 69:3554-3559

Luytjes W, Bredenbeek PJ, Noten AF, Horzinek MC, Spaan WJ (1988) Sequence of mouse hepatitis virus A59 mRNA 2: indications for RNA recombination between coronaviruses and influenza $C$ virus. Virology 166:415-422 
Ma AS, Moran-Jones K, Shan J, Munro TP, Snee MJ, Hoek KS, Smith R (2002) hnRNP A3, a novel RNA trafficking response element binding protein. J Biol Chem 8:8

Mahy BW, Siddell S, Wege H, ter Meulen V (1983) RNA-dependent RNA polymerase activity in murine coronavirus-infected cells. J Gen Virol 64:103-111

Makino S, Joo M, Makino JK (1991) A system for study of coronavirus mRNA synthesis: a regulated, expressed subgenomic defective interfering RNA results from intergenic site insertion. J Virol 65:6031-6041

Martin JP, Koehren F, Rannou JJ, Kirn A (1988) Temperature-sensitive mutants of mouse hepatitis virus type 3 (MHV-3): isolation, biochemical and genetic characterization. Arch Virol 100:147-160

Mayeda A, Munroe SH, Caceres JF, Krainer AR (1994) Function of conserved domains of hnRNP A1 and other hnRNP A/B proteins. EMBO J 13:5483-5495

Meerovitch K, Svitkin YV, Lee HS, Lejbkowicz F, Kenan DJ, Chan EK, Agol VI, Keene JD, Sonenberg N (1993) La autoantigen enhances and corrects aberrant translation of poliovirus RNA in reticulocyte lysate. J Virol 67:3798-3807

Michael WM, Siomi H, Choi M, Pinol-Roma S, Nakielny S, Liu Q, Dreyfuss G (1995) Signal sequences that target nuclear import and nuclear export of pre-mRNAbinding proteins. Cold Spring Harb Symp Quant Biol 60:663-668

Miller DJ, Schwartz MD, Ahlquist P (2001) Flock house virus RNA replicates on outer mitochondrial membranes in Drosophila cells. J Virol 75:11664-11676

Molenkamp R, van Tol H, Rozier BC, van der Meer Y, Spaan WJ, Snijder EJ (2000) The arterivirus replicase is the only viral protein required for genome replication and subgenomic mRNA transcription. J Gen Virol 81:2491-2496

Moyer SA, Baker SC, Horikami SM (1990) Host cell proteins required for measles virus reproduction. J Gen Virol 71:775-783

Moyer SA, Baker SC, Lessard JL (1986) Tubulin: a factor necessary for the synthesis of both Sendai virus and vesicular stomatitis virus RNAs. Proc Natl Acad Sci USA 83:5405-5409

Nanda SK, Leibowitz JL (2001) Mitochondrial aconitase binds to the $3^{\prime}$ untranslated region of the mouse hepatitis virus genome. J Virol 75:3352-3362

Nelson GW, Stohlman SA, Tahara SM (2000) High affinity interaction between nucleocapsid protein and leader/intergenic sequence of mouse hepatitis virus RNA. J Gen Virol 81:181-188

Neufeld KL, Richards OC, Ehrenfeld E (1991) Purification, characterization, and comparison of poliovirus RNA polymerase from native and recombinant sources. J Biol Chem 266:24212-24219

Niepmann M (1996) Porcine polypyrimidine tract-binding protein stimulates translation initiation at the internal ribosome entry site of foot-and-mouth-disease virus. FEBS Lett 388:39-42

Niepmann M, Petersen A, Meyer K, Beck E (1997) Functional involvement of polypyrimidine tract-binding protein in translation initiation complexes with the internal ribosome entry site of foot-and-mouth disease virus. J Virol $71: 8330-8339$

Oglesbee MJ, Liu Z, Kenney H, Brooks CL (1996) The highly inducible member of the $70 \mathrm{kDa}$ family of heat shock proteins increases canine distemper virus polymerase activity. J Gen Virol 77:2125-2135 
Osman TA, Buck KW (1997) The tobacco mosaic virus RNA polymerase complex contains a plant protein related to the RNA-binding subunit of yeast eIF-3. J Virol 71:6075-6082

Pardigon N, Strauss JH (1996) Mosquito homolog of the La autoantigen binds to Sindbis virus RNA. J Virol 70:1173-1181

Parsley TB, Towner JS, Blyn LB, Ehrenfeld E, Semler BL (1997) Poly (rC) binding protein 2 forms a ternary complex with the $5^{\prime}$-terminal sequences of poliovirus RNA and the viral 3CD proteinase. RNA 3:1124-1134

Perlman S, Ries D, Bolger E, Chang LJ, Stoltzfus CM (1986) MHV nucleocapsid synthesis in the presence of cycloheximide and accumulation of negative strand MHV RNA. Virus Res 6:261-272

Pinol-Roma S, Dreyfuss G (1992) Shuttling of pre-mRNA binding proteins between nucleus and cytoplasm. Nature 355:730-732

Pinon JD, Mayreddy RR, Turner JD, Khan FS, Bonilla PJ, Weiss SR (1997) Efficient autoproteolytic processing of the MHV-A59 3C-like proteinase from the flanking hydrophobic domains requires membranes. Virology 230:309-322

Pinon JD, Teng H, Weiss SR (1999) Further requirements for cleavage by the murine coronavirus 3C-like proteinase: identification of a cleavage site within ORF1b. Virology 263:471-484

Pogue GP, Huntley CC, Hall TC (1994) Common replication strategies emerging from the study of diverse groups of positive-strand RNA viruses. Arch Virol Suppl 9:181-194

Quadt R, Kao CC, Browning KS, Hershberger RP, Ahlquist P (1993) Characterization of a host protein associated with brome mosaic virus RNA-dependent RNA polymerase. Proc Natl Acad Sci USA 90:1498-1502

Robb JA, Bond CW (1979) Pathogenic murine coronaviruses. I. Characterization of biological behavior in vitro and virus-specific intracellular RNA of strongly neurotropic JHMV and weakly neurotropic A59V viruses. Virology 94:352-370

Rothstein MA, Richards OC, Amin C, Ehrenfeld E (1988) Enzymatic activity of poliovirus RNA polymerase synthesized in Escherichia coli from viral cDNA. Virology 164:301-308

Sachs AB, Sarnow P, Hentze MW (1997) Starting at the beginning, middle, and end: translation initiation in eukaryotes. Cell 89:831-838

Sawicki SG, Sawicki DL (1986) Coronavirus minus-strand RNA synthesis and effect of cycloheximide on coronavirus RNA synthesis. J Virol 57:328-334

Schaad MC, Stohlman SA, Egbert J, Lum K, Fu K, Wei T, Jr., Baric RS (1990) Genetics of mouse hepatitis virus transcription: identification of cistrons which may function in positive and negative strand RNA synthesis. Virology 177:634-645

Schalinske KL, Chen OS, Eisenstein RS (1998) Iron differentially stimulates translation of mitochondrial aconitase and ferritin mRNAs in mammalian cells. Implications for iron regulatory proteins as regulators of mitochondrial citrate utilization. J Biol Chem 273:3740-3746

Schiller JJ, Kanjanahaluethai A, Baker SC (1998) Processing of the coronavirus MHV-JHM polymerase polyprotein: identification of precursors and proteolytic products spanning 400 kilodaltons of ORF1a. Virology 242:288-302

Schmid SR, Linder P (1992) D-E-A-D protein family of putative RNA helicases. Mol Microbiol 6:283-291 
Schwartz M, Chen J, Janda M, Sullivan M, den Boon J, Ahlquist P (2002) A positivestrand RNA virus replication complex parallels form and function of retrovirus capsids. Mol Cell 9:505-514

Schwarz B, Routledge E, Siddell SG (1990) Murine coronavirus nonstructural protein ns2 is not essential for virus replication in transformed cells. J Virol 64:47844791

Seybert A, Hegyi A, Siddell SG, Ziebuhr J (2000) The human coronavirus 229E superfamily 1 helicase has RNA and DNA duplex-unwinding activities with $5^{\prime}$-to- $3^{\prime}$ polarity. RNA 6:1056-1068

Shen X, Masters PS (2001) Evaluation of the role of heterogeneous nuclear ribonucleoprotein $\mathrm{A} 1$ as a host factor in murine coronavirus discontinuous transcription and genome replication. Proc Natl Acad Sci USA 98:2717-2722

Shi ST, Huang P, Li HP, Lai MMC (2000) Heterogeneous nuclear ribonucleoprotein A1 regulates RNA synthesis of a cytoplasmic virus. EMBO J 19:4701-4711

Shi ST, Schiller JJ, Kanjanahaluethai A, Baker SC, Oh JW, Lai MM (1999) Colocalization and membrane association of murine hepatitis virus gene 1 products and de novo-synthesized viral RNA in infected cells. J Virol 73:5957-5969

Shi ST, Yu GY, Lai MMC (2003) Multiple type A/B heterogeneous nuclear ribonucleoproteins (hnRNPs) can replace hnRNP A1 in mouse hepatitis virus RNA synthesis. J Virol 11:10584-10593

Sims AC, Ostermann J, Denison MR (2000) Mouse hepatitis virus replicase proteins associate with two distinct populations of intracellular membranes. J Virol 74:5647-5654

Siomi H, Dreyfuss G (1995) A nuclear localization domain in the hnRNP A1 protein. J Cell Biol 129:551-560

Snijder EJ, van Tol H, Roos N, Pedersen KW (2001) Non-structural proteins 2 and 3 interact to modify host cell membranes during the formation of the arterivirus replication complex. J Gen Virol 82:985-994

Sokolowski M, Schwartz S (2001) Heterogeneous nuclear ribonucleoprotein C binds exclusively to the functionally important UUUUU-motifs in the human papillomavirus type-1 AU-rich inhibitory element. Virus Res 73:163-175

Spagnolo JF, Hogue BG (2000) Host protein interactions with the $3^{\prime}$ end of bovine coronavirus RNA and the requirement of the poly(A) tail for coronavirus defective genome replication. J Virol 74:5053-5065

Spangberg K, Wiklund L, Schwartz S (2000) HuR, a protein implicated in oncogene and growth factor mRNA decay, binds to the $3^{\prime}$ ends of hepatitis $\mathrm{C}$ virus RNA of both polarities. Virology 274:378-390

Stalcup RP, Baric RS, Leibowitz JL (1998) Genetic complementation among three panels of mouse hepatitis virus gene 1 mutants. Virology 241:112-121

Stohlman SA, Baric RS, Nelson GN, Soe LH, Welter LM, Deans RJ (1988) Specific interaction between coronavirus leader RNA and nucleocapsid protein. J Virol 62:4288-4295

Svitkin YV, Ovchinnikov LP, Dreyfuss G, Sonenberg N (1996) General RNA binding proteins render translation cap dependent. EMBO J 15:7147-7155

Tahara S, Bergmann C, Nelson G, Anthony R, Dietlin T, Kyuwa S, Stohlman S (1993) Effects of mouse hepatitis virus infection on host cell metabolism. Adv Exp Med Biol 342:111-116 
Tahara SM, Dietlin TA, Bergmann CC, Nelson GW, Kyuwa S, Anthony RP, Stohlman SA (1994) Coronavirus translational regulation: leader affects mRNA efficiency. Virology 202:621-630

Tahara SM, Dietlin TA, Nelson GW, Stohlman SA, Manno DJ (1998) Mouse hepatitis virus nucleocapsid protein as a translational effector of viral mRNAs. Adv Exp Med Biol 440:313-318

Tan BH, Fu J, Sugrue RJ, Yap EH, Chan YC, Tan YH (1996) Recombinant dengue type 1 virus NS5 protein expressed in Escherichia coli exhibits RNA-dependent RNA polymerase activity. Virology 216:317-325

Tarun SZ, Jr., Sachs AB (1996) Association of the yeast poly(A) tail binding protein with translation initiation factor eIF-4G. EMBO J 15:7168-7177

Tarun SZ, Jr., Wells SE, Deardorff JA, Sachs AB (1997) Translation initiation factor eIF4G mediates in vitro poly(A) tail-dependent translation. Proc Natl Acad Sci USA 94:9046-9051

Thiel V, Herold J, Schelle B, Siddell SG (2001) Viral replicase gene products suffice for coronavirus discontinuous transcription. J Virol 75:6676-6681

Thiel V, Siddell SG (1994) Internal ribosome entry in the coding region of murine hepatitis virus mRNA 5. J Gen Virol 75:3041-3046

Tijms MA, van Dinten LC, Gorbalenya AE, Snijder EJ (2001) A zinc finger-containing papain-like protease couples subgenomic mRNA synthesis to genome translation in a positive-stranded RNA virus. Proc Natl Acad Sci USA 98:1889-1894

Valcarcel J, Gebauer F (1997) Post-transcriptional regulation: the dawn of PTB. Curr Biol 7:R705-708

van der Meer Y, Snijder EJ, Dobbe JC, Schleich S, Denison MR, Spaan WJ, Locker JK (1999) Localization of mouse hepatitis virus nonstructural proteins and RNA synthesis indicates a role for late endosomes in viral replication. J Virol 73:76417657

van Dinten LC, den Boon JA, Wassenaar AL, Spaan WJ, Snijder EJ (1997) An infectious arterivirus cDNA clone: identification of a replicase point mutation that abolishes discontinuous mRNA transcription. Proc Natl Acad Sci USA 94:991996

van Dinten LC, Rensen S, Gorbalenya AE, Snijder EJ (1999) Proteolytic processing of the open reading frame $1 \mathrm{~b}$-encoded part of arterivirus replicase is mediated by nsp4 serine protease and Is essential for virus replication. J Virol 73:2027-2037

van Dinten LC, Wassenaar AL, Gorbalenya AE, Spaan WJ, Snijder EJ (1996) Processing of the equine arteritis virus replicase ORF1b protein: identification of cleavage products containing the putative viral polymerase and helicase domains. J Virol 70:6625-6633

Van Dyke TA, Flanegan JB (1980) Identification of poliovirus polypeptide P63 as a soluble RNA-dependent RNA polymerase. J Virol 35:732-740

Wang Y, Zhang X (1999) The nucleocapsid protein of coronavirus mouse hepatitis virus interacts with the cellular heterogeneous nuclear ribonucleoprotein A1 in vitro and in vivo. Virology 265:96-109

Wang YF, Chen SC, Wu FY, Wu CW (1997) The interaction between human cytomegalovirus immediate-early gene 2 (IE2) protein and heterogeneous ribonucleoprotein A1. Biochem Biophys Res Commun 232:590-594 
Weighardt F, Biamonti G, Riva S (1995) Nucleo-cytoplasmic distribution of human hnRNP proteins: a search for the targeting domains in hnRNP A1. J Cell Sci 108:545-555

Williams GD, Chang RY, Brian DA (1995) Evidence for a pseudoknot in the $3^{\prime}$ untranslated region of the bovine coronavirus genome. Adv Exp Med Biol 380:511514

Wu-Baer F, Lane WS, Gaynor RB (1996) Identification of a group of cellular cofactors that stimulate the binding of RNA polymerase II and TRP-185 to human immunodeficiency virus 1 TAR RNA. J Biol Chem 271:4201-4208

Yokomori K, Banner LR, Lai MM (1991) Heterogeneity of gene expression of the hemagglutinin-esterase (HE) protein of murine coronaviruses. Virology 183:647657

Yokomori K, Lai MM (1991) Mouse hepatitis virus S RNA sequence reveals that nonstructural proteins ns4 and ns5a are not essential for murine coronavirus replication. J Virol 65:5605-5608

Yu W, Leibowitz JL (1995a) A conserved motif at the $3^{\prime}$ end of mouse hepatitis virus genomic RNA required for host protein binding and viral RNA replication. Virology 214:128-138

Yu W, Leibowitz JL (1995b) Specific binding of host cellular proteins to multiple sites within the $3^{\prime}$ end of mouse hepatitis virus genomic RNA. J Virol 69:2016-2023

Yuan ZH, Kumar U, Thomas HC, Wen YM, Monjardino J (1997) Expression, purification, and partial characterization of HCV RNA polymerase. Biochem Biophys Res Commun 232:231-235

Zhang X, Lai MMC (1995a) Interactions between the cytoplasmic proteins and the intergenic (promoter) sequence of mouse hepatitis virus RNA: correlation with the amounts of subgenomic mRNA transcribed. J Virol 69:1637-1644

Zhang X, Li HP, Xue W, Lai MMC (1999) Formation of a ribonucleoprotein complex of mouse hepatitis virus involving heterogeneous nuclear ribonucleoprotein A1 and transcription-regulatory elements of viral RNA. Virology 264:115-124

Zhang X, Liao CL, Lai MMC (1994) Coronavirus leader RNA regulates and initiates subgenomic mRNA transcription both in trans and in cis. J Virol 68:4738-4746

Zhang XM, Lai MMC (1995b) Regulation of coronavirus RNA transcription is likely mediated by protein-RNA interactions. Adv Exp Med Biol 380:515-521

Ziebuhr J, Siddell SG (1999) Processing of the human coronavirus 229E replicase polyproteins by the virus-encoded 3C-like proteinase: identification of proteolytic products and cleavage sites common to pp1a and pplab. J Virol 73:177-185

Ziebuhr J, Snijder EJ, Gorbalenya AE (2000) Virus-encoded proteinases and proteolytic processing in the Nidovirales. J Gen Virol 81:853-879 